\title{
A Methodology for Surface Soil Moisture and Vegetation Optical Depth Retrieval Using the Microwave Polarization Difference Index
}

\author{
Manfred Owe, Richard de Jeu and Jeffrey Walker
}

\author{
Hydrological Sciences Branch \\ NASA/Goddard Space Flight Center \\ Greenbelt, MD 20771
}

\begin{abstract}
A methodology for retrieving surface soil moisture and vegetation optical depth from satellite microwave radiometer data is presented. The procedure is tested with historical $6.6 \mathrm{GHz}$ brightness temperature observations from the Scanning Multichannel Microwave Radiometer over several test sites in Illinois. Results using only nighttime data are presented at this time, due to the greater stability of nighttime surface temperature estimation. The methodology uses a radiative transfer model to solve for surface soil moisture and vegetation optical depth simultaneously using a non-linear iterative optimization procedure. It assumes known constant values for the scattering albedo and roughness. Surface temperature is derived by a procedure using high frequency vertically polarized brightness temperatures. The methodology does not require any field observations of soil moisture or canopy biophysical properties for calibration purposes and is totally independent of wavelength. Results compare well with field observations of soil moisture and satellite-derived vegetation index data from optical sensors.
\end{abstract}




\section{A Methodology for Surface Soil Moisture and Vegetation Optical Depth Retrieval Using the Microwave Polarization Difference Index

\author{
Manfred Owe, Richard de Jeu and Jeffrey Walker
}

\section{Significant Findings}

\section{Question:}

Is it possible to solve the radiative transfer equation to derive surface soil moisture without information on the vegetation cover or soil moisture ground observations for calibration.

\section{Approach:}

A methodology for retrieving surface soil moisture and vegetation optical from satellite microwave radiometer data has been developed. The approach uses a radiative transfer model to solve for surface soil moisture and vegetation optical depth with a nonlinear iterative optimization procedure. Results compared well with field observations of soil moisture and satellite-derived vegetation index data from optical sensors.

\section{Significance and Implications of Findings:}

This approach does not require any field observations of soil moisture or canopy biophysical properties for calibration purposes, and is totally independent of wavelength. It permits the retrieval of global surface moisture fields from satellite microwave observations. This procedure can provide historical data sets of global surface moisture from archived satellite microwave data, near-real time estimates, and could be valuable for initialization and as an input parameter for General Circulation Models.

\section{Relation to Earth Science Enterprise:}

The interpretation of satellite microwave observations for soil moisture determination has strong relevance within the Earth Science Enterprise Program, especially in land cover and use change, seasonal to interannual climate variability and prediction, and climate change research. The significance of this methodology increases with the inclusion of a microwave instrument on the new AQUA platform. 


\title{
A Methodology for Surface Soil Moisture and Vegetation Optical Depth Retrieval Using the Microwave Polarization Difference Index
}

\author{
Manfred Owe, Richard de Jeu and Jeffrey Walker
}

\section{Popular Summary}

A new procedure for estimating global soil moisture from microwave sensors on Earthorbiting satellites has been developed. This method uses a physically based equation, known as a radiative transfer relationship, and is unique in that it does not require measurements of ground data that have traditionally been necessary for calibration purposes. In addition, the procedure also estimates the vegetation optical depth. The optical depth is a measure of the amount of vegetation which overlies the surface. Together, these two variables can provide researchers with valuable information about the moisture status of the Earth's surface. Such information may be important for a variety of applications, such as drought monitoring, determining flooding potential, various agricultural applications, and estimating fire danger. 


\section{INTRODUCTION}

The retrieval of soil moisture from satellite microwave observations has received sporadic emphasis during the past 20 years, with only a few groups devoting any significant effort to this area of study [1] - [3]. Recently, however, interest in satellite microwavè research has increased as a result of the anticipated launch of several new remote sensing platforms which include microwave sensors.

Surface moisture is an important link between the land surface and the atmosphere, directly influencing the exchange of heat and moisture between these two sinks, and as such is an important element in the global circulation process. Surface soil moisture has been identified as a parameter of significant potential for improving the accuracy of large-scale land surface-atmosphere interaction models. However, soil moisture is often somewhat difficult to measure accurately in both time and space, especially at large spatial scales. It changes constantly as a result of precipitation events, evapotranspiration processes, and redistribution within the soil. Spatially, soil moisture is highly variable on both the small and large scale, due to the variability of precipitation and the heterogeneity of the land surface (e.g. vegetation, soil physical properties, topography, etc.). While point sampling of soil moisture is generally thought to be the most accurate, the observation is representative only of a relatively small area immediately surrounding the sample location. Subsequent areal averaging of point measurements, especially at scales of $10^{2}-10^{3} \mathrm{~km}^{2}$, will often introduce large errors. Since remotely sensed land surface measurements are already spatially averaged, they are a logical input to regional or larger-scale land process models. Regular and improved estimates of soil moisture have been shown to significantly enhance the performance of 
global circulation models (GCM) [4], [5] and certain mesoscale models, such as flood forecast models.

While the radiative transfer mechanisms which describe the emission of microwave energy both from the soil and vegetation are for the most part known, the inverse problem of separating observed brightness temperature at satellite altitudes into its component parts is still not entirely straight forward. A number of obstacles have contributed to this difficulty, and may be summarized as follows:

- Large number of emission processes which contribute to the satellite observation.

- The non-linearity of many of the emission processes and the difficulty in quantifying these complex physical relationships.

- Coarse spatial resolution of satellite microwave radiometers.

- The inhomogeneity of the land surface and the inherent spatial variability of soil physical properties, especially at satellite scales.

- Lack of optimal validation data sets, such as large-scale spatially representative surface moisture observations.

Current radiative transfer theory is difficult to apply over vegetated areas, due to inadequate knowledge about the optical depth. Traditional methodologies have attempted to relate remotely sensed estimates of soil moisture to observational ground data, and then solve for the optical depth as a residual. These approaches are not ideal because of poor ground-based data sets, and the inability to quantify spatially representative estimates of surface soil moisture and vegetation biophysical properties at satellite scales. Recently, Njoku and Li [1] have developed an approach which uses 6 microwave bands (three frequencies at 2 polarizations each) to solve for three land surface parameters. The methodology described in this paper is unique, in 
that it uses only the horizontal and vertical bands of one frequency to solve simultaneously for surface soil moisture and the vegetation optical depth, without the use surface observations of soil moisture or any other land surface property for calibration or tuning purposes. The approach uses a theoretical radiative transfer model and the microwave polarization difference index, and is tested with $6.6 \mathrm{GHz}$ Scanning Multichannel Microwave Radiometer (SMMR) data over two footprint-sized test sites in Illinois. The study is limited to analyzing nighttime data because of the greater reliability of surface temperature estimation during the night. Results are compared with soil moisture field observations, precipitation data, and satellite-derived vegetation index data.

\section{MICROWAVE THEORY}

Passive microwave remote sensing is based on the measurement of thermal radiation from the land surface in the centimeter wave band, which is determined by the physical temperature and the emissivity of the radiating body. In the microwave region, the emitted radiation is extremely low as compared with longwave infrared radiation. An approximation for the Planck equation, at low frequencies $(f<117 \mathrm{GHz})$, is the Rayleigh-Jeans approximation, and can be shown to lead to

$$
T_{b} \cong e_{S} T
$$

where $T_{b}$ is the observed microwave brightness temperature, $T$ is the physical (thermometric) temperature of the emitting layer, and $e_{S}$ is the smooth-surface emissivity. Emissivity is further defined as

$$
e_{S}=\left(1-R_{S}\right)
$$


where $\mathrm{R}_{\mathrm{S}}$ is the smooth-surface reflectivity. While the absolute magnitude of the soil emissivity is somewhat lower at horizontal polarization, the sensitivity to changes in surface moisture is significantly greater than at vertical polarization (Figure 1). Conversely, at vertical polarization, the sensitivity to surface temperature is greater. This subsequently forms the basis for a surface temperature estimation procedure [6], which is discussed later. For a more thorough treatment of electromagnetic theory, the reader is referred to Ulaby et al. [7].

\section{A. Dielectric Constant}

The microwave region is the only part of the electromagnetic spectrum that permits truly quantitative estimates of soil moisture using physically based expressions such as radiative transfer models. Microwave technology is also the only remote sensing method that measures a direct response to the absolute amount of water in the surface soil. The basis for microwave remote sensing of soil moisture follows from the large contrast in dielectric constant of dry soil $(\sim 4)$ and water $(-80)$ and the resulting dielectric properties of soil-water mixtures $(4-40)$ and their effect on the natural microwave emission from the soil [8]. The dielectric constant is an electrical property of matter and is a measure of the response of a medium to an applied electric field. The dielectric constant is a complex number, containing a real $\left(k^{\prime}\right)$ and an imaginary $\left(k^{\prime}\right)$ part. The real part determines the propagation characteristics of the energy as it passes upward through the soil, while the imaginary part determines the energy losses [8]. The dielectric constant is a difficult quantity to measure in the field. Moreover, reproducing precise field conditions in laboratory soil samples makes laboratory analyses of the dielectric constant not entirely straightforward. Consequently, the validation of theoretical calculations is often somewhat difficult. Two dielectric 
models which are commonly used in theoretical calculations are the Dobson Model [11] and the Wang-Schmugge Model [12]. Schmugge [8] presents an excellent review of basic microwave theory.

\section{B. Soil Physical Properties}

In a non-homogeneous medium such as soil, the complex dielectric constant is a combination of the individual dielectric constants of its components (i.e. air, water, rock, etc.). In a soil medium, the dielectric constant is determined largely by the moisture content, temperature, salinity, textural composition, and frequency.

The relationship between the soil dielectric constant and the moisture content is almost linear, except at low moisture contents (Fig. 2). This non-linearity at low moisture contents is due to the strong bonds which develop between the surfaces of the soil particles and the thin films of water which surround them. These bonds are so strong at low moisture levels, that the free rotation of the water molecules is impeded. This water is often referred to as bound water. Therefore, in a relatively dry soil, the water is tightly bound and contributes little to the dielectric constant of the soil water mixture. As more water is added, the molecules are further from the particle surface and are able to rotate more freely. This is referred to as the free water phase. The subsequent influence of the free water on the soil dielectric constant therefore also increases. Smaller particles such as irregular fine sands, silts, and clays have a higher surface area-to-volume ratio and therefore are able to hold more water molecules at higher potentials. The unique plate-like structure of clays provides an additional source of high energy bonds and increases the soil's affinity for water. Two soils with different textural composition may exhibit markedly different relationships between moisture content and their respective soil dielectric constants. Soils with a high clay content will generally 
have lower a dielectric constant than coarse sandy soils at the same moisture content, since more water is being held in the bound water phase (Fig. 2).

\section{Soil Moisture Sampling Depth}

Microwave energy originates from within the soil, and the magnitude of any one soil layer's contribution decreases with depth. For practical purposes, the total thickness of the surface layer which provides most of the measurable energy contribution is defined as the thermal sampling depth [9]. It is also often referred to as the skin depth or penetration depth. The energy which is subsequently emitted from the soil surface is highly affected by the dielectric contrast across the soil-air interface, causing some of the energy to be reflected back downward into the soil. The amount of energy which is reflected back is directly related to the magnitude of this dielectric contrast. The thickness of this layer which determines the surface emissivity/reflectivity is often referred to as the soil moisture sampling depth, and is thought to be only several tenths of a wavelength thick [10]. It is the average dielectric properties of this layer that determine the observed emissivity. However, this thickness varies as a function of the average moisture content of the layer in addition to wavelength, polarization, and incidence angle. As the average moisture content of this layer decreases, its thickness increases. It is the average moisture content of this soil layer which is most strongly related to the emissivity observed above the surface.

\section{Surface Roughness}

Surface roughness increases the emissivity of natural surfaces, and is caused by increased scattering due to the increase in surface area of the emitting surfaces [8]. Roughness also reduces the sensitivity of emissivity to soil moisture variations, and thus reduces the range in 
measurable emissivity from dry to wet soil conditions [13]. An empirical roughness model was developed by Choudhury et al. [14], and is described as

$$
\mathrm{e}_{\mathrm{r}}=1-\mathrm{R}_{0} \exp \left(-\mathrm{h} \cos ^{2} u\right)
$$

where $h$ is an empirical roughness parameter, related to the root mean square (rms) height variation of the surface and the correlation length, and $u$ is the incidence angle of the observation. Typical values for $\mathrm{h}$ have been suggested, ranging from 0 for a smooth surface, 0.3 for a disked field, to 0.5 for a rough plowed field.

A more elaborate formulation, which also included a polarization mixing parameter, has subsequently been proposed by Wang and Choudhury [15]. However, little work has since been conducted to quantify the relative magnitudes of either the roughness parameter or the polarization mixing parameter. The effects of frequency and incidence angle on the roughness parameter have also not been studied thoroughly. The effect of roughness on the observed microwave brightness at $6.6 \mathrm{GHz}$ for a range of surface moistures is illustrated in figure 3. A change in the roughness parameter from 0 to 0.3 corresponds to a difference in the surface emissivity, of about 0.005 at dry conditions, to about 0.014 at saturation. There is some speculation that the effect of surface roughness is minimal in most locations at satellite scales, except in areas of mountainous terrain or extreme relief.

\section{E. Vegetation Effects}

The effects of vegetation on the microwave emission as measured from above the canopy is two-fold. The vegetation may absorb or scatter the radiation emanating from the soil, but it will also emit its own radiation. In areas of sufficiently dense canopy, the emitted soil radiation 
will become masked out, and the observed emissivity will be due largely to the vegetation. The magnitude of the absorption depends upon the wavelength and the water content of the vegetation. The most frequently used wavelengths for soil moisture sensing are in the $\mathrm{L}$ - and $\mathrm{C}$ bandwidths $(\lambda \cong 21 \mathrm{~cm}$ and $5 \mathrm{~cm})$, although only L-band sensors are able to penetrate vegetation of any significant density. While observations at all frequencies are subject to scattering and absorption and require some correction if the data are to be used for soil moisture retrieval, shorter wave bands are especially susceptible to vegetation influences.

Numerous canopy models have been developed to account for the effects of vegetation [7], [16] - [18]. These basic models have been modified and applied successfully by a variety of investigators, using data from primarily ground-based radiometer systems over agricultural fields [19] - [21]. Radiative transfer characteristics of vegetation can be expressed in terms of the transmissivity, $\Gamma$, and the single scattering albedo, $\omega$. The transmissivity is defined in terms of the optical depth $\tau$, such that

$$
\Gamma=\exp (-\tau / \cos u)
$$

The optical depth is related to the canopy density, and for frequencies less than $10 \mathrm{GHz}$, has been shown to be linear function of vegetation water content. Typical values of $\tau$ for agricultural crops have generally been given as less than one [17], [21]. Theoretical calculations show that the sensitivity of above-canopy brightness temperature measurements to variations in soil emissivity decreases with increasing optical depth or canopy thickness [7]. This is because the soil emission is attenuated by the canopy and emission from the vegetation canopy tends to saturate the signal with increasing optical depth. This subsequently results in decreased sensor 
sensitivity to soil moisture variations. A transmissivity of 1 corresponds to an optical depth of 0 , indicating bare soil, or at least no attenuation of the soil-emitted radiation due to an overlying canopy. Conversely, a transmissivity of 0 indicates an infinitely thick canopy, with no penetration of the soil emission through the canopy.

The theoretical relationship between the vegetation optical depth and the transmissivity is illustrated in figure 4. It is also shown in figure 5, that at C-band, the above-canopy signal becomes totally saturated at an optical depth of about 1.5 in the horizontal channel, although for practical purposes, the sensitivity is already quite low above 0.75 . Under dry conditions, this threshold occurs even sooner. The relationships between other indicators of vegetation biomass or canopy density, such as leaf area index (LAI), vegetation water content (VWC), Microwave Polarization Difference Index (MPDI) and Normalized Difference Vegetation Index (NDVI) have been reported in a variety of studies [22] - [24], but are largely empirical in nature. Theoretical calculations indicate that at C-band, sensitivity to changes in surface moisture conditions ceases at a maximum VWC of approximately $1.5 \mathrm{~kg} \mathrm{~m}^{-2}[1]$.

The single scattering albedo describes the scattering of the soil emissivity by the vegetation. The scattering albedo is a function of plant geometry, and consequently varies according to plant species and associations. Experimental data for this parameter are limited, and values for selected crops have been found to vary from 0.04 to about 0.12 [17], [21], [25]. Values for natural vegetation are even more scarce, although Becker and Choudhury [22] estimated a value of 0.05 for a semi-arid region in Africa. Van de Griend and Owe [26] calculated a 3-year time series of both scattering albedo and canopy optical depth at both 6.6 $\mathrm{GHz}$ and $37 \mathrm{GHz}$ for savannas of Botswana. The optical depth displayed a distinct seasonal course at both frequencies, although the values for $37 \mathrm{GHz}$ were significantly higher. While the 
scattering albedo demonstrated considerable variability during the 3-year period, a relationship with vegetation biomass or other seasonal indicators was not observed. An average value for the scattering albedo of 0.076 was found for both frequencies. The effect of the scattering albedo on the observed brightness temperature-surface moisture relationship is illustrated in figure 6, over a range of values reported in the literature.

The influence of polarization on the optical depth and the scattering albedo has also received relatively little attention. There is, however, some experimental evidence that differences in the transmissivity at horizontal and vertical polarization are dependent on incidence angle. These differences are observed mainly over vegetation elements that exhibit some systematic orientation such as vertical stalks in tall grasses, grains, and maize [7], [26], [27]. At a nadir $\left(0^{\circ}\right)$ incidence angle, the stalks are not visible, and appear only as small randomly oriented disks. However, as the incidence angle increases, the stalks become more prominent, resulting in an increased effect on vertically polarized emissions. In general, the canopy and stem structure for most crops and naturally occurring vegetation are randomly oriented, and it is reasonable to assume that the leaf absorption loss factor is for the most part polarization independent. This tendency of vegetation to reduce the polarization difference with increasing biomass is the basis for the Microwave Polarization Difference Index (MPDI) [22].

\section{F. Physical Surface Temperature}

Satellite microwave observations are generally recorded as brightness temperatures, which must be normalized by the physical temperature of the surface soil as given in Eq. (1). The surface layer known as the soil moisture sampling depth is generally thought to determine the surface emissivity [10], and it is the temperature of this layer that should be used to 
normalize the observed satellite brightness. It has been noticed [28] that in semi-arid regions, nighttime brightness temperatures display a significantly higher response to variations in surface moisture content than daytime brightness temperatures. Several factors may account for this phenomenon. First, daytime surface heating is extremely high and variable in these regions. This usually causes severe drying of the surface layer. Such intense heating also increases the difficulty in making accurate spatially representative surface temperature estimates. At night, some moisture is restored to the surface as it regains some equilibrium with the underlying soil. Additionally, the temperatures of the air, soil surface, and canopy tend to approach some equilibrium, making it somewhat easier to estimate spatially averaged surface temperature at night.

\section{G. Atmosphere}

Electromagnetic radiation emitted from the ground surface may interact with the atmosphere in two ways as it propagates to a satellite radiometer. These are interactions between the electromagnetic radiation and 1) atmospheric gases (primarily oxygen and water vapor) and 2) water droplets existing in clouds and rain. The primary interaction mechanism is that of absorption of energy by the atmosphere. However, for frequencies below $15 \mathrm{GHz}$ the effects are quite small, and for frequencies below $10 \mathrm{GHz}$ the effects are negligible. The effect of water droplets in clouds and rain may be somewhat more significant, and depends largely on two factors; 1) the phase state of the particles (i.e. ice or liquid) and 2) the size of the particle relative to the wavelength [29], [30].

In addition to the atmospheric effects on the emitted surface radiation, there is also a sky background radiation component, which is reflected back to the observing instrument, and also a 
direct atmospheric component. Each of these components is further affected (attenuated) by the atmospheric transmissivity. As stated before, these effects are relatively small at longer wavelengths, and have been excluded from the present analysis. However, in order to further minimize adverse atmospheric effects, satellite observations during times of active precipitation were eliminated from the data set. Additionally, satellite observations were also not included in the analysis when surface temperatures were below zero.

\section{SATELLITE DATA}

The microwave data used to illustrate the proposed methodology are from the Scanning Multichannel Microwave Radiometer (SMMR) on board the Nimbus-7 satellite [31]. The instrument began transmitting data in October of 1978, and was eventually deactivated in August of 1987. Due to power constraints on board the satellite, the SMMR instrument could only be activated on alternate days. The satellite orbited the Earth approximately 14 times in one day, with a local noon (ascending orbit) and midnight (descending orbit) equator crossing, and a swath width of about $780 \mathrm{~km}$. Brightness temperatures were measured at five frequencies, from $6.6 \mathrm{GHz}(\lambda \cong 4.5 \mathrm{~cm})$ to $37 \mathrm{GHz}(\lambda \cong 0.8 \mathrm{~cm})$ at both horizontal and vertical polarization, resulting in ten different channels. Although complete coverage of the Earth required about 6 days, sufficient overlapping occurred at the mid-latitudes, to result in repeat coverage over small sites about 2 to 3 times per week. The 24 hour on-off cycle of the instrument still permitted both day and night observations, which for research purposes, was an ideal feature. While the spatial resolution of SMMR was rather coarse (from approximately $25 \mathrm{~km}$ at $37 \mathrm{GHz}$ to $150 \mathrm{~km}$ at 6.6 $\mathrm{GHz}$ ), these data still have highly useful applications, especially at regional, continental, and global scales. 
The original SMMR data were obtained from the Marshall Space Flight Center Distributed Active Archive Center (DAAC). Orbit brightness temperatures were extracted and binned into daily $1 / 4$ degree global maps. If a pixel center fell within a grid, then the grid is assigned the brightness value. If multiple pixel centers fell within a $1 / 4$ degree grid, then all the brightness values within the grid were averaged. Separate daytime and nighttime datasets were created.

\section{MODELLING APPROACH}

The methodology presented here solves for the soil moisture and optical depth simultaneously, using the simple radiative transfer equation, eq. (5) below, and the horizontal and vertical brightness temperature at a single frequency. The upwelling radiation from the land surface as observed from above the canopy may be expressed in terms of the radiative brightness temperature, $T_{b}$, and is given as a simple radiative transfer equation [17],

$$
\mathrm{T}_{\mathrm{b}(\mathrm{P})}=\mathrm{T}_{\mathrm{S}} \mathrm{e}_{\mathrm{r}(\mathrm{P})} \Gamma_{(\mathrm{P})}+\left(1-\omega_{(\mathrm{P})}\right) \mathrm{T}_{\mathrm{C}}\left(1-\Gamma_{(\mathrm{P})}\right)+\left(1-\mathrm{e}_{\mathrm{T}}(\mathrm{P})\right)\left(1-\omega_{(\mathrm{P})}\right) \mathrm{T}_{\mathrm{C}}\left(1-\Gamma_{(\mathrm{P})}\right) \Gamma_{(\mathrm{P})}
$$

where $P$ refers to either horizontal or vertical polarization, $T_{S}$ and $T_{C}$ are the thermometric temperatures of the soil and the canopy respectively, $\omega$ is the single scattering albedo, and the transmissivity, $\Gamma$, is defined in terms of the optical depth, $\tau$, as in eq. (4). The first term of the above equation defines the radiation from the soil as attenuated by the overlying vegetation. The second term accounts for the upward radiation directly from the vegetation, while the third term defines the downward radiation from the vegetation, reflected upward by the soil and again attenuated by the canopy. 
A nominal satellite footprint size of $150 \mathrm{~km}^{2}$ is assumed. Even though pixels are registered to a $1 / 4$ degree grid, all retrieval calculations, including ancillary data, are based on the assumed footprint size. A uniform footprint, with respect to average soil and canopy temperatures and vegetation biophysical characteristics is assumed. Surface moisture and canopy optical depth are subsequently extracted as average footprint values. Since there are still many more variables than can be solved for effectively by the radiative transfer relationships, some elements will have to be estimated and/or solved for independently.

As stated earlier, information on the scattering albedo is somewhat scarce. While most reported values have been estimated primarily as residual calculations using theoretical approaches with radiative transfer models, limited information exists on validation efforts from actual field measurements. Based on reported scattering albedo values and the effect of the scattering albedo on the observed brightness temperature that was illustrated in figure 6 , an average value of 0.06 is used. It was also assumed that surface roughness would have a minimum effect on the surface moisture calculations over the test area. Van de Griend and Owe [26] found that a surface roughness of 0 gave the lowest rms errors in satellite-derived surface moisture over a southern African test site. Surface roughness was subsequently set to 0 .

Estimating spatially representative land surface temperature, especially at larger, satellite scales, has traditionally been difficult and often imprecise. The spatial variability of surface temperature is usually high, due to the differences in land cover, albedo, and other topographic effects, so simple averaging of a few point measurements usually leads to large errors. Surface temperature estimates that are based on air temperature measurements have often given more accurate results, because air temperature itself is usually more spatially representative when measured in appropriate locations. Based on the increased homogeneity of nighttime air, canopy 
and soil surface temperatures, it was decided to first test the approach with nighttime SMMR data only.

The physical surface temperature of the SMMR footprint was estimated by a procedure, which uses vertically polarized $37 \mathrm{GHz}$ brightness temperatures [6]. This approach is based on the increased sensitivity of $\mathrm{V}$ - polarized $\mathrm{T}_{\mathrm{b}}$ to the surface physical temperature rather than to the surface emissivity (Eq. 1). The relationship between $\mathrm{V}$-polarized $37 \mathrm{GHz} \mathrm{T}_{\mathrm{b}}$ and air temperature observed at 2400 hours at several test sites in Illinois is illustrated (figure 7). Also shown is field data (figure 8), which illustrates the relationship between air temperature and surface soil temperature at $1 \mathrm{~cm}$, measured both in the open and under a canopy. While soil temperature measured under a canopy is seen to fall along the 1:1 line with air temperature, soil temperature in the open is observed to be somewhat lower. The brightness temperature-air temperature relationship (figure 7) was subsequently adjusted downward, in order to provide a more representative estimate of the soil moisture sampling depth temperature. The possibility for improvements to the surface temperature estimation procedure is currently being investigated, with several extensive field data sets of surface soil temperature and $37 \mathrm{GHz}$ ground-based radiometer measurements.

While some experimental evidence has shown that the vegetation optical depth at both horizontal and vertical polarization are the same, it is important that this assumption undergo additional validation. This was achieved by analyzing areas where the surface soil moisture was know, namely areas of saturation. Daily and hourly precipitation records throughout the Midwest were analyzed for the entire SMMR period for exceptionally large storms. The criteria was that these storms not only had to deposit large amounts of water to ensure saturation of the surface, but they also had to cover an extensive geographic area, to ensure near complete 
coverage of the SMMR footprint. Storm events with greater than $30 \mathrm{~mm}$ average precipitation for an entire footprint in a 24-hour period were selected. All gauging stations within the footprint must have recorded rain during the period. An additional stipulation was that a satellite overpass had to occur between 4 and 8 hours after end of the precipitation event. The footprint locations used in this analysis are given in figure 9 and cover a range of canopy types and densities. Assuming complete saturation of the surface, and knowledge of the soil porosity and texture, the soil emissivity can be calculated easily by using a dielectric model [12] and the Fresnel [1] equations. The radiative transfer equation (Eq. 5) is then inverted and solved for the optical depth, for both vertical and horizontal polarization. It is noticed that when $\tau_{\mathrm{H}}$ and $\tau_{\mathrm{V}}$, where plotted against each other (Fig. 10), there was a primarily 1:1 relationship for the two optical depths.

The model now has two remaining parameters; the vegetation parameter or optical depth and the soil moisture parameter, which is expressed as the emissivity. Solving for these two variables, however, requires a more novel approach, and is described below.

Brightness temperature measured from space contains information on both the canopy and soil surface emissions and their respective physical temperatures (Eq. 1). Polarization ratios, such as the Microwave Polarization Difference Index (MPDI), are frequently used to remove the temperature dependence of $T_{b}$, resulting in a parameter that is quantitatively, and more highly, related to the dielectric properties of all the emitting surface(s). At the $37 \mathrm{GHz}$ frequency, the MPDI is mainly a function of the overlying vegetation, and consequently a good indicator of the canopy density, due to its relatively short wavelength [22]. At a frequency of $6.6 \mathrm{GHz}$, the MPDI will also contain information on the canopy, namely the optical depth, but will also 
contain significantly more information on the soil emission and consequently the soil dielectric properties. The MPDI is defined as

$$
M P D I=\left(T_{b(V)}-T_{b(H)}\right) /\left(T_{b(V)}+T_{b(H)}\right)
$$

The theoretical relationship between the MPDI and the canopy optical depth as derived from the radiative transfer equation, is illustrated in figure 11. This relationship was derived by running numerous simulations of $\mathrm{T}_{\mathrm{b}(\mathrm{V})}$ and $\mathrm{T}_{\mathrm{b}(\mathrm{H})}$ for different dielectric constants and optical depth. As one notices, however, the relationship between the optical depth and MPDI exhibits a strong dependence on the surface moisture, and is defined by a family of curves according to the surface moisture content. Instead of using soil moisture, however, the absolute value of the soil dielectric constant is used in order to eliminate the influence of soil physical properties. These curves may be defined by fitting an empirical function to the simulations, according to

$$
\tau=C_{1} \ln \left(C_{2} X+C_{3}\right)
$$

where $X$ is the MPDI and $C_{1}, C_{2}$, and $C_{3}$ are coefficients which may be defined as a function of the absolute value of the soil dielectric constant (see figure 12 and Table 1)

$$
C_{j}=P_{j . l} k^{N}+P_{j .2} k^{(N \cdot l)}+\ldots P_{j . N} k+P_{j .(N+I)}
$$

By substitution of Eq (7) in Eq. (5), the optical depth is eliminated and the vegetation parameter in the radiative transfer model is now only a function of the dielectric constant. Validation of the empirical optical depth relationship in Eq. (7) against the original simulations using the radiative 
transfer equations is given in figure 13. The theoretical optical depth, as derived by solving the radiative transfer equation, is plotted together with the model simulation results for two soil moisture values. Agreement between the two solutions is good. The remaining term in the radiative transfer equation (Eq. 5) is the soil emissivity, $\mathrm{e}_{\mathrm{T}(\mathrm{H})}$. The emissivity of the soil is calculated from the Fresnel equation (for $\mathrm{H}$ polarization) [1], where the only unknown is the complex dielectric constant of the soil.

We now have the remaining two parameters, the canopy optical depth and the soil emissivity, both defined in terms of the soil dielectric constant. Next, the model uses a nonlinear iterative procedure, the Brent Method [32], to solve the radiative transfer equation (Eq. 5) in a forward approach, by optimizing on the dielectric constant. The Brent procedure is a preferred technique for solving the root of a general one dimensional function when the derivative is not easily found. Once convergence of the calculated and observed brightness temperature is achieved, the model uses soil information on particle size distribution, porosity, and wilting point from a data base of soil physical characteristics from the Land Data Assimilation System (LDAS) [33] for our N. American application, together with the WangSchmugge dielectric model [12], to solve for the surface soil moisture.

\section{RESULTS OF SMMR RETRIEVALS}

The methodology outlined above for retrieval of both surface soil moisture and vegetation optical depth has been applied to the entire historical data set of nighttime SMMR brightness temperatures for Illinois. This area is selected because of the availability of long-term observational soil moisture data [34] that can be used for validation purposes. While not necessarily the most optimum data set for microwave validation, it is one of the few soil 
moisture data sets in the world, and possibly the only one in the U.S., that covers such a large area for such a lengthy period. The soil moisture data are reported as average volumetric moisture content in the top $10 \mathrm{~cm}$ soil profile. A total of 19 soil moisture sampling sites are located throughout the state. Two $150 \mathrm{~km}$ test sites were selected for illustration (figure 15), with each site containing 3 observation stations. Six-year time series of SMMR-derived surface moistures along with the observed soil moistures from the three stations within the test sites are given in figure 16. However, one must keep in mind several important differences, when comparing the satellite-derived surface moistures with the ground observations.

- Differences in spatial resolution - The SMMR-derived surface moisture is an average value integrated over the entire footprint, whereas the observational data are point measurements.

- Differences in vertical resolution - the observational data are an average soil moisture within the top $10 \mathrm{~cm}$ profile, while the SMMR retrievals reflect only the moisture content of the microwave soil moisture sampling depth, which is at most only about $1 \mathrm{~cm}$.

- Differences in acquisition times - Ground and satellite observations rarely occur on the same day.

- Inter-observation periods -While the SMMR observations are displayed with connecting lines, it is done so only to help in observing general trends in the time series. It is important to realize that significant changes in surface moisture frequently occur during the periods between observations, but may go totally undetected by both the satellite and the ground observations. Daily precipitation is also included in the time series to assist in understanding the observed changes in soil moisture. 
Time series of the retrieved optical depths for the same test sites are also given in figure 17. Fifteen day NDVI composite data are averaged for the SMMR footprint, and are included for comparison. A distinct annual course is observed in the optical depth time series, and coincides well with the NDVI. The optical depth, however, is seen to be much more variable in time than the NDVI. This is due to the inherent characteristics of the NDVI compositing procedure, where only one value is selected during the composite window to represent the entire !

period. The inability to quantify the vegetation biomass at shorter (i.e. daily) time scales is often a drawback of the NDVI. This may be rather significant in arid and semi-arid regions, where greening and browning of the vegetation canopy (especially grasses) can occur over very short time periods in response to a precipitation event. The microwave optical depth may actually be a better indicator of green biomass and vegetation dynamics at shorter time scales. However, it is also important to understand that the NDVI and the microwave optical depth respond to different vegetation properties. The NDVI responds to differences in the reflectivities of visible (red) and near infrared wave bands, and is influenced by several canopy properties, including not only leaf water content, but color as well. The microwave optical depth, on the other hand, responds primarily to the vegetation water content, as a function of the vegetation dielectric properties.

\section{DISCUSSION AND CONCLUSIONS}

A methodology is presented, that retrieves pixel average surface soil moisture and vegetation optical depth from dual polarized microwave brightness temperature observations, and has been applied to the $6.6 \mathrm{GHz}$ SMMR data. The radiative transfer-based approach does not use ground observations of soil moisture, canopy measurement data, or other regional/geophysical data as calibration parameters, and is totally independent of frequency. 
However, some assumptions regarding the different elements of the radiative transfer equation are made, in order to reduce the number of variables. The model assumes a constant value for the scattering albedo, based on a series of previous studies, and derives surface temperature from high frequency $(37 \mathrm{GHz})$ vertically polarized brightness temperature data. A soil roughness parameter was not included during this analysis, however, improvements resulting from the inclusion of a roughness parameter based on land use or topographic data, especially in $\checkmark$ mountainous or other extreme terrain will also be investigated in the near future. Only nighttime data was used in the study because of the greater stability of nighttime surface temperatures. Days with snow cover or when surface temperatures were below zero were eliminated from the analysis. A non-linear iterative approach is used to solve for the surface moisture and vegetation optical depth, both of which are derived from the soil dielectric constant.

The present study was limited to the Illinois area as a demonstration, because of the availability of long-term soil moisture observations for comparison. Time series of the satellitederived surface moisture compared well with the available ground observations and precipitation data. Likewise, optical depth compared well with 15-day NDVI composite data. Validation studies in other regions are currently being conducted. Unfortunately, reliable, spatially averaged surface moisture data, which can be used for validation purposes are rare to nonexistent, especially at satellite scales. Comparisons with precipitation fields is often the only validation option available. Field experiments with the express purpose of gathering such data should be designed and implemented as a research priority. Refinements to a $37 \mathrm{GHz}$ daytime surface temperature retrieval algorithm will be completed shortly, allowing for daytime soil moisture retrievals to be conducted, with the eventual goal of generating a complete retrospective daytime and nighttime global surface moisture dataset for the entire SMMR period. 


\section{REFERENCES}

[1] E.G. Njoku and $\mathrm{Li} \mathrm{Li}$, "Retrieval of land surface parameters using passive microwave measurements at 6-18 GHz", IEEE Trans. Geosci. Remote Sensing, vol. 37, pp. 79-93, Jan. 1999.

[2] M. Owe, A.A. Van de Griend, R. de Jeu, J.J. de Vries, E. Seyhan and E.T. Engman, "Estimating soil moisture from satellite microwave observations: Past and ongoing projects, and relevance to GCIP", J. Geophys. Research, vol. 104, pp. 19,735-19,742, 1999.

[3] T.J. Jackson, "Soil moisture estimation using special satellite microwave/imager satellite data over a grassland region", Water Resour. Res., vol. 33, pp. 1475-1484, 1997.

[4] J. Shukla and Y. Mintz, "Influence of land-surface evapotranspiration on the Earth's climate", Science, vol. 215, pp. 1498-1500, 1982,

[5] P.A. Dirmeyer, F.J. Zeng, A. Ducharne, J. Morill and R.D. Koster, "The sensitivity of surface fluxes to soil water content in three land surface schemes", J. Hydrometeorology, (In Press).

[6] M. Owe and A.A. Van de Griend, "On the relationship between thermodynamic surface temperature and high frequency $(37 \mathrm{GHz}$ ) vertical polarization brightness temperature under semi-arid conditions", Int. J. Remote Sensing, (In Press).

[7] F.T. Ulaby, R.K. Moore and A.K. Fung, Microwave Remote Sensing Active and Passive, vol. III. Boston, MA: Artech House, 1986.

[8] T.J. Schmugge, Remote sensing of soil moisture, in Hydrological Forecasting, edited by M.G. Anderson and T.P. Burt, John Wiley, New York, 1985. 
[9] T.J. Schmugge and B.J. Choudhury, "A comparison of radiative transfer models for predicting the microwave emission from soils", Radio Science, vol. 16, pp. 927-938, 1981.

[10] T.J. Schmugge, "Remote sensing of soil moisture: Recent advances", IEEE Trans. Geosci. Remote Sensing, vol. 21, pp. 336-344, July 1983.

[11] M.C. Dobson, F.T. Ulaby, M.T. Hallikainen and M.A. El-Rayes, "Microwave dielectric behavior of wet soil - Part I: Dielectric mixing models", IEEE Trans. Geosci. Remote Sensing, vol. 23, pp. 35-46, Jan. 1985.

[12] J.R. Wang and T.J. Schmugge, "An empirical model for the complex dielectric permittivity of soil as a function of water content", IEEE Trans. Geosci. Remote Sensing, vol. 18, pp. 288-295, Oct. 1980.

[13] J.R. Wang, "Passive microwave sensing of soil moisture content: The effects of soil bulk density and surface roughness", Remote Sens. Environ., vol. 13, pp. 329-344, 1983.

[14] B.J. Choudhury, T.J. Schmugge, A.T.C. Chang and R.W. Newton, "Effect of surface roughness on the microwave emission from soils, J. Geophys. Res., vol. 84, pp. 5699-5705, 1979.

[15] J.R. Wang and B.J. Choudhury, "Remote sensing of soil moisture content over bare field at $1.4 \mathrm{GHz}$ frequency, J. Geophys. Res., vol. 86, pp. 5277-5282, 1981.

[16] K.P. Kirdiashev, A.A. Chukhlantsev and A.M. Shutko, "Microwave radiation of the Earth's surface in the presence of vegetation cover", Radio Eng. Electronics, vol. 24, pp. 256-264, 1979. 
[17] T. Mo, B.J. Choudhury, T.J. Schmugge, J.R. Wang and T.J. Jackson, "A model for microwave emission from vegetation-covered fields", J. Geophys. Res., vol. 87, pp. 11,229-11,237, 1982.

[18] S.W. Theis, and B.J. Blanchard, "The effect of measurement error and confusion from vegetation on passive microwave estimates of soil moisture", Int. J. Rem. Sens., vol. 9, pp. $333-340,1988$.

[19] T.J. Jackson, T.J. Schmugge and J.R. Wang, "Passive microwave sensing of soil moisture under vegetation canopies", Water Resours. Res., Vol. 18, pp. 1137-1142, 1982.

[20] P. Pampaloni, and S. Paloscia, "Microwave emission and plant water content: a comparison between field measurements and theory", IEEE Geosci. Remote Sensing, vol. 24, pp. 900$905,1986$.

[21] T.J. Jackson and P.E. O'Neill, "Attenuation of soil microwave emission by corn and soybeans at 1.4 and 5 GHz", IEEE Trans. Geosci. Remote Sens., vol. 28, pp. 978-980, 1990.

[22] F. Becker and B.J. Choudhury, "Relative sensitivity of normalized difference vegetation index (NDVI) and microwave polarization difference index (MPDI) for vegetation and desertification monitoring", Rem. Sens. Environ., vol. 24, pp. 297-311, 1988.

[23] C.J. Tucker, J.H. Elgin and J.E. McMurtrey, "Relationship of crop radiance to alfalfa agronomic values", Int. J. Remote Sens., vol. 1, pp. 69-75, 1980.

[24] B.N. Holben, C.J. Tucker and C-J. Fan, "Spectral assessment of soybean leaf area and leaf biomass", Photogrammetric Eng. and Remote Sens., vol. 46, pp. 651-656, 1980.

[25] D.R. Brunfeldt and F.T. Ulaby, "Measured Microwave Emission and Scattering in Vegetation Canopies. IEEE Trans. Geosci. Remote Sens., vol. 22, pp. 520-524, 1984. 
[26] A.A. Van de Griend and M. Owe, "Microwave vegetation optical depth and inverse modelling of soil emissivity using Nimbus/SMMR satellite observations", Meteorology and Atmospheric Physics, vol. 54, pp. 225-239, 1994.

[27] A.A. Van de Griend, M. Owe, J. de Ruiter and B.T. Gouweleeuw, "Measurement and behavior of dual-polarization vegetation optical depth and single scattering albedo at 1.4 and $5 \mathrm{GHz}$ microwave frequencies", IEEE Trans. Geosci. and Remote Sens., vol. 34, pp. 957-965, 1996.

[28] M. Owe, A.A. Van de Griend and A.T.C Chang, "Surface moisture and satellite microwave observations in semiarid southern Africa”, Water Resour. Res., vol. 28, pp. 829-839, 1992.

[29] F.T. Ulaby, R.K. Moore and A.K. Fung, Microwave Remote Sensing Active and Passive, vol. I. Boston, MA: Artech House, 1982.

[30] M.T. Chahine, "Interaction mechanisms within the atmosphere", in Manual of Remote Sensing, edited by R.N. Colwell, pp. 165-230, 1983.

[31] P. Gloersen and F.T. Barath, "A scanning multichannel microwave radiometer for Nimbus-G and SeaSat-A", IEEE J. Oceanic Engineering, vol. 2, pp. 172-178, 1977.

[32] W.H. Press, B.P. Flannery, S.A. Teukolsky and W.T. Vetterling, Numerical Recipes. New York: Cambridge Univ. Press, chap. 9, 1997.

[33] P.R. Houser, B.A. Cosgrove, J.K. Entin and M. Desetty "Land data assimilation system", http://ldas.gsfc.nasa.gov/index.shtml, NASA/Goddard Space Flight Center, 2000.

S.E. Hollinger and S.A. Isard, "A soil moisture climatology of Illinois", J. of Climate, vol. 7, pp. 822-833, 1994. 


\section{FIGURES}

1. Comparison of horizontal and vertical polarized emissivity calculated for an average soil at the SMMR wavelength and incidence angle with no canopy cover.

2. Comparison of the soil dielectric constants for typical sand, loam, and clay soils. The real part is designated by $k^{\prime}$ and the imaginary part by $k$ ".

3. Horizontal polarized brightness temperature calculated for a range of roughness values using Eq. 3 is illustrated.

4. The relationship between the canopy optical depth and the transmissivity.

5. The effect of the canopy optical depth on the emissivity. At H-polarization, the sensitivity of the above-canopy emissivity is severely reduced at an optical depth of about $0.75(\Gamma=0.3)$ and totally saturated due to vegetation at 1.5 .

6. The effect of the scattering albedo on the soil moisture brightness temperature relationship.

7. Relationship between the $37 \mathrm{GHz}$ vertical brightness temperature and ( 2400 hour) air temperature at climate stations throughout Illinois.

8. Field observations relating air and soil $(0-1 \mathrm{~cm})$ temperature.

9. Locations of SMMR footprints used to calculate the vertical and horizontal optical depth at saturated conditions.

10. Relationship between vertical and horizontal optical depth.

11. The theoretical relationship between MPDI and the canopy optical depth for a range of soil dielectric constants.

12. Relationship between the absolute value of the soil dielectric constant and the three coefficients used to calculate the canopy optical depth from the MPDI. 
13. Validation comparing the MPDI-optical depth relationship derived from the radiative transfer equation to calculations from simulated data.

14. Map showing locations of soil moisture observation stations.

15. Six year time series of soil moisture retrievals for the northern (a) and southern (b) test sites. Ground observations of soil moisture, as well as the average daily footprint precipitation are also indicated for comparison.

16. Six year time series of satellite-derived optical depth are illustrated for the northern (a) and southern (b) test sites. Time series of 15-day NDVI composites are also plotted for comparison. 
Table 1. Polynomial parameters for Eq. (8), that describe the relationship between $\mathrm{k}$ and the fitting parameters $C_{l}, C_{2}$, and $C_{3}$.

\begin{tabular}{cccc}
\hline$j$ & 1 & 2 & 3 \\
\hline$P_{j .1}$ & $-7674772 \times 10^{-12}$ & $7.735033 \times 10^{-9}$ & $4.728134 \times 10^{-13}$ \\
$P_{j .2}$ & $1.040412 \times 10^{-9}$ & $-1.107934 \times 10^{-6}$ & $-6.531554 \times 10^{-11}$ \\
$P_{j .3}$ & $-5.936831 \times 10^{-8}$ & $6.6721781 \times 10^{-5}$ & $3.825192 \times 10^{-9}$ \\
$P_{j .4}$ & $1.855700 \times 10^{-6}$ & $-2.224984 \times 10^{-3}$ & $-1.239732 \times 10^{-7}$ \\
$P_{j .5}$ & $-3.472915 \times 10^{-5}$ & $4.533959 \times 10^{-2}$ & $2.440707 \times 10^{-6}$ \\
$P_{j .6}$ & $4.025172 \times 10^{-4}$ & $-5.631002 \times 10^{-1}$ & $-3.032079 \times 10^{-5}$ \\
$P_{j .7}$ & $-2.962942 \times 10^{-3}$ & 4.228538 & $2.420843 \times 10^{-4}$ \\
$P_{j .8}$ & $1.581774 \times 10^{-2}$ & -17.90242 & $-1.264989 \times 10^{-3}$ \\
$P_{j .9}$ & $-3581621 \times 10^{-1}$ & 39.10880 & $-1.920510 \times 10^{-3}$
\end{tabular}




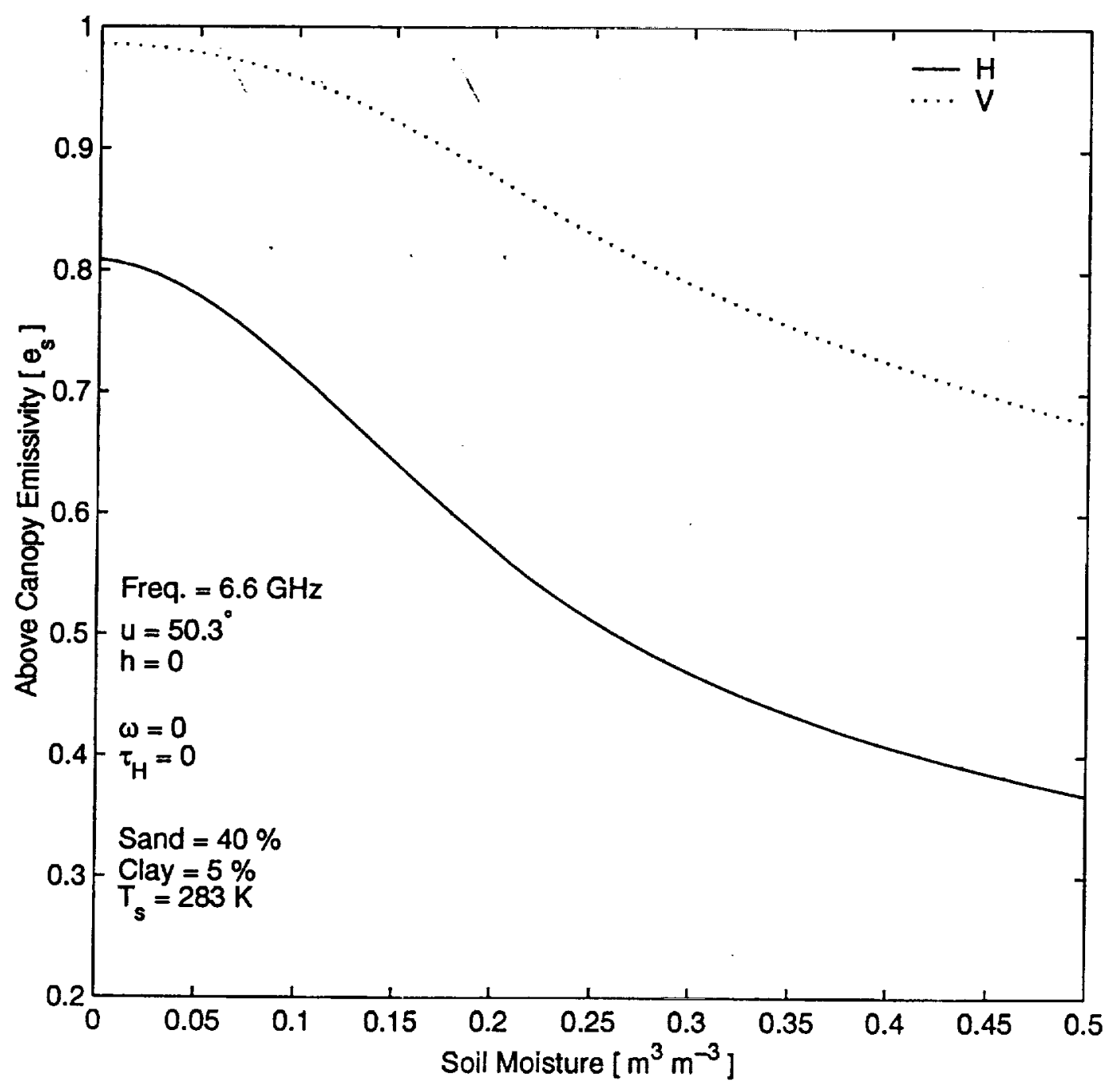




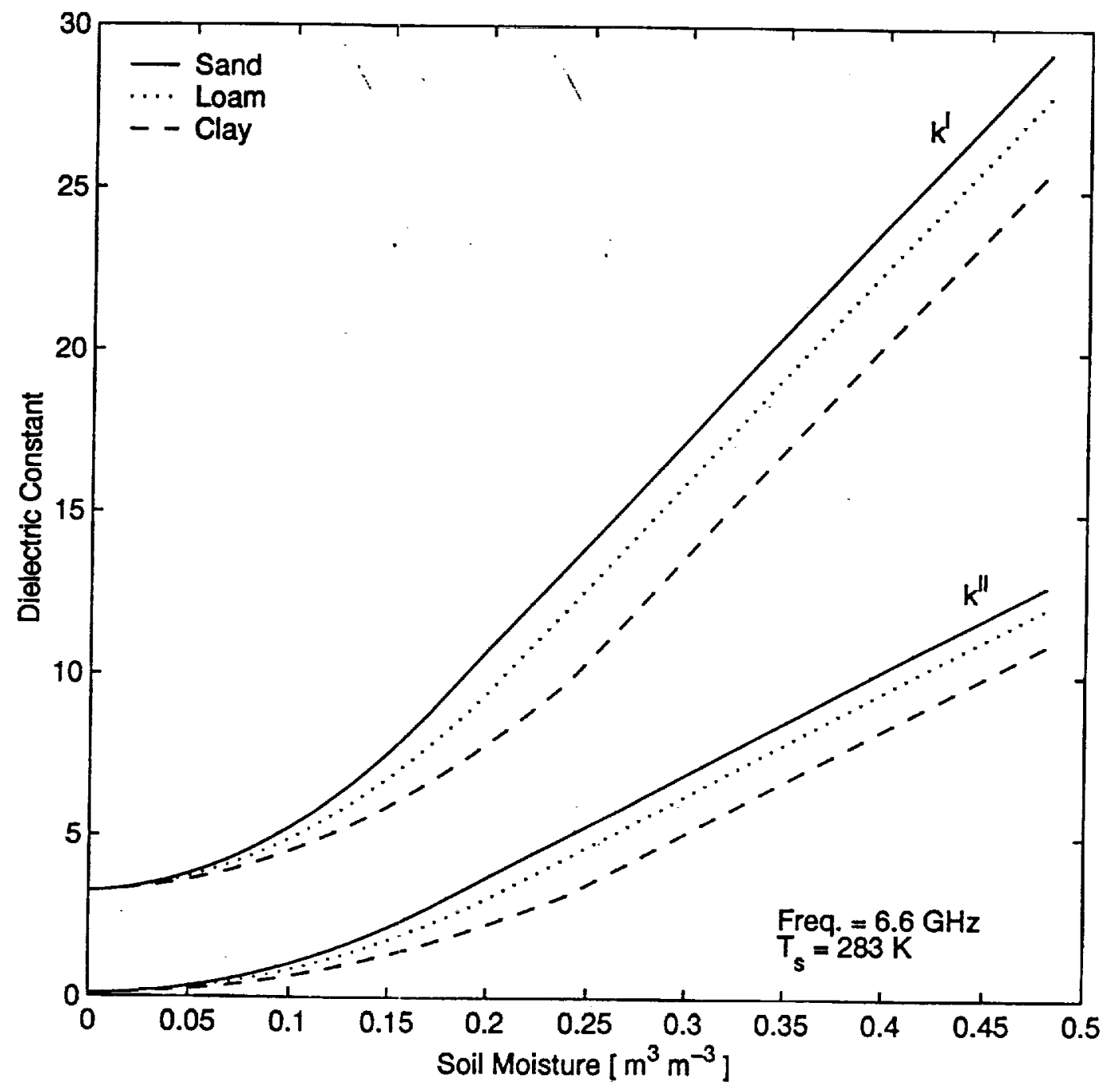

(2) 


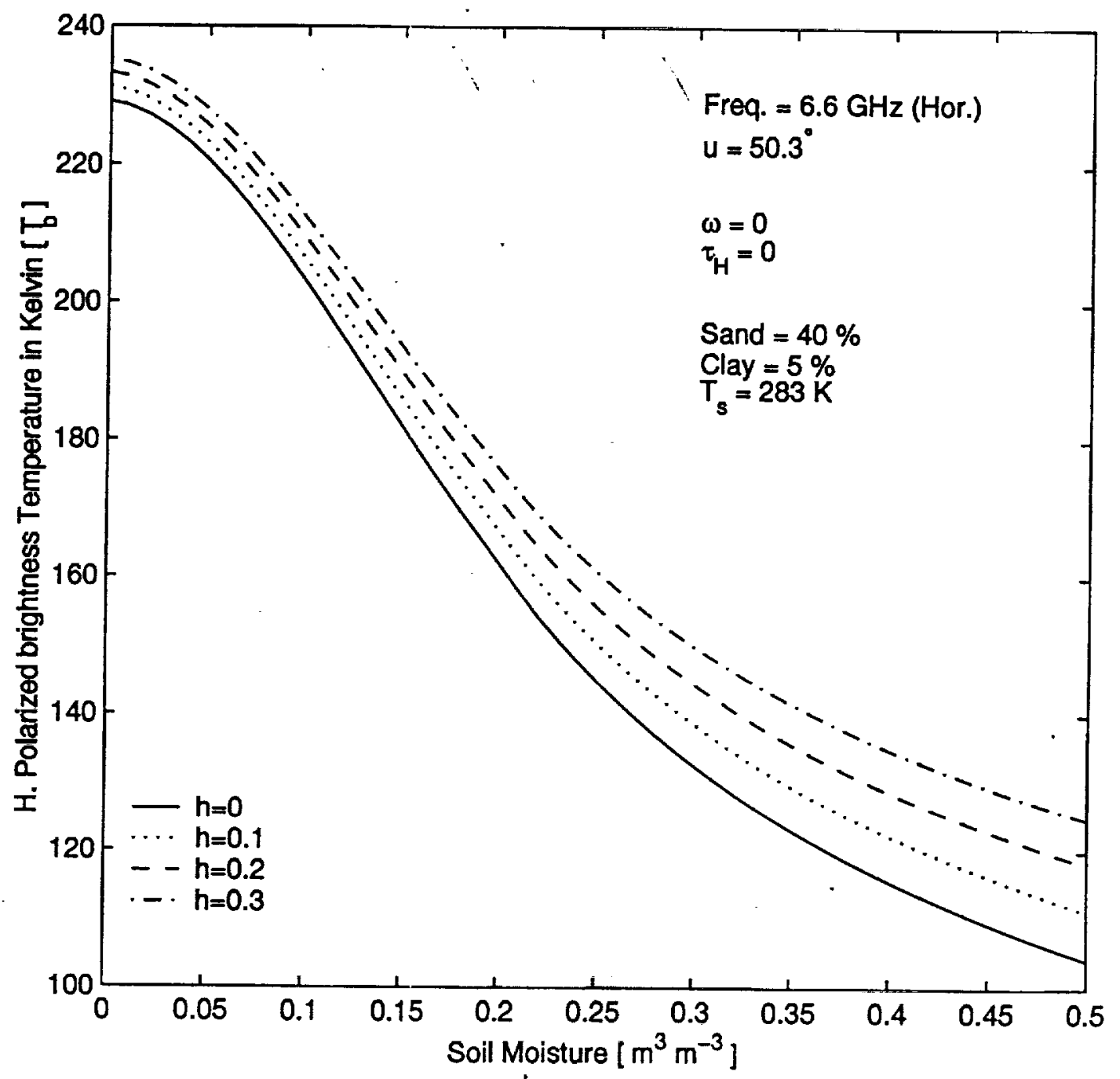




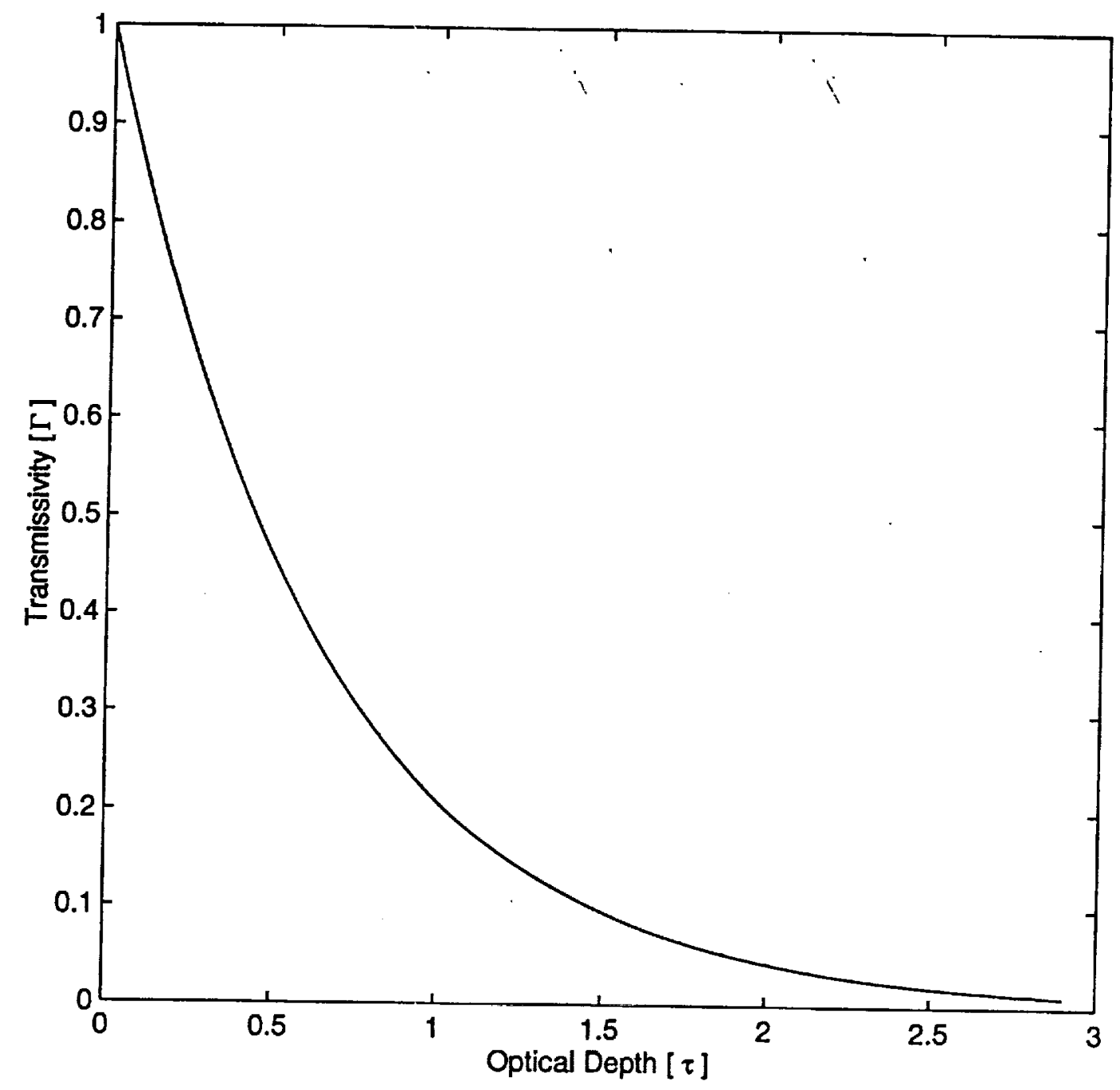

(4) 


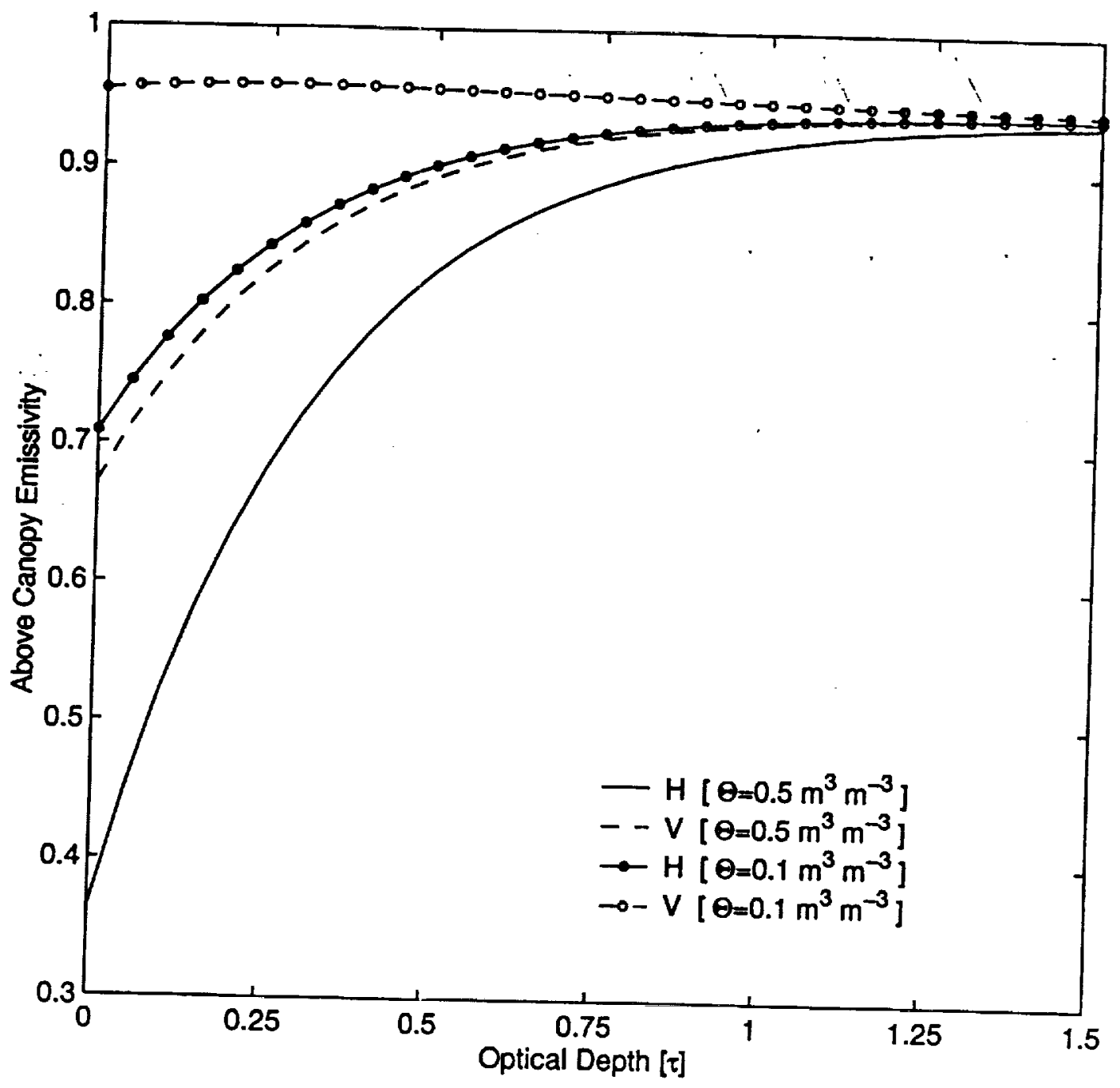




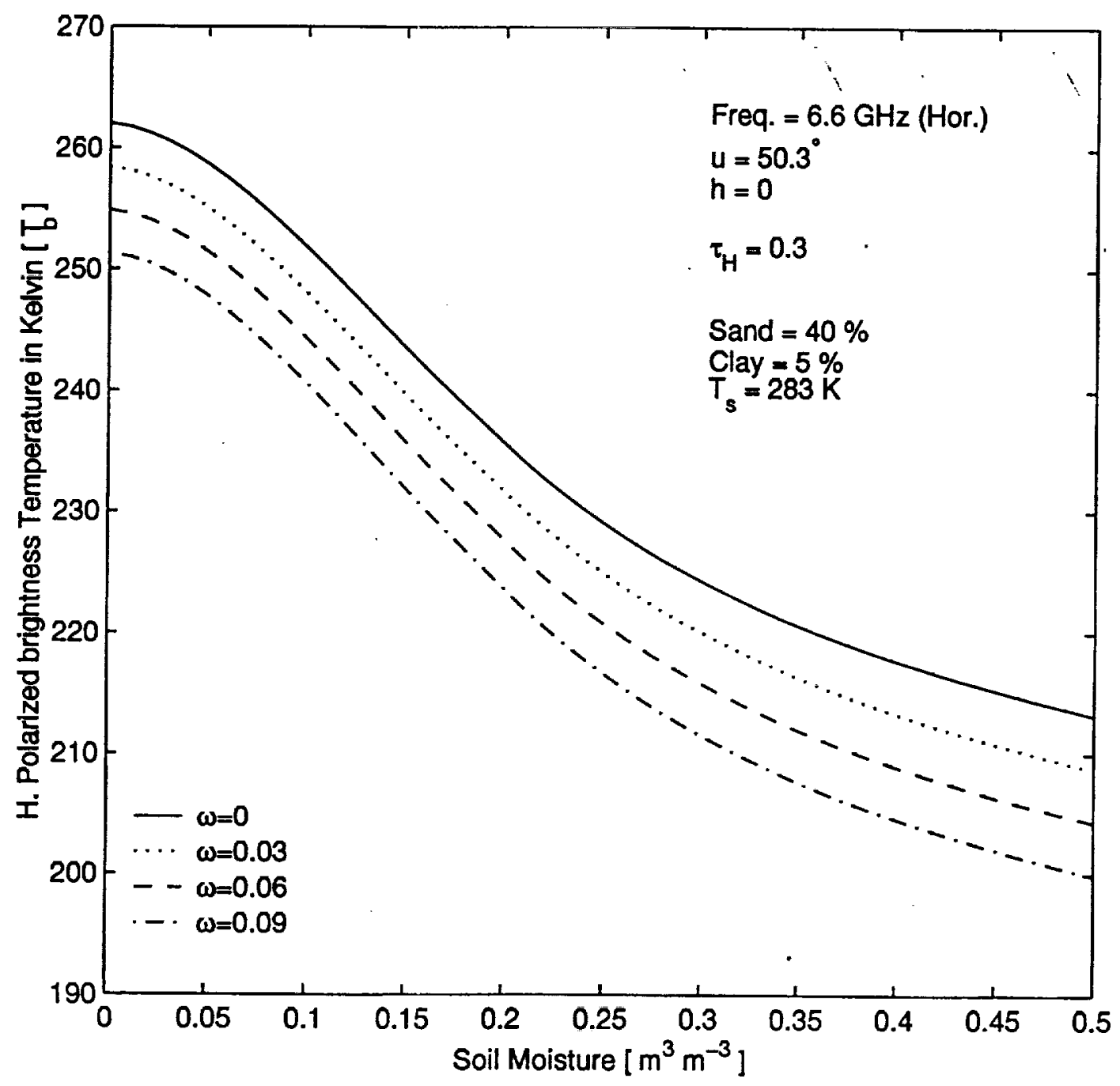




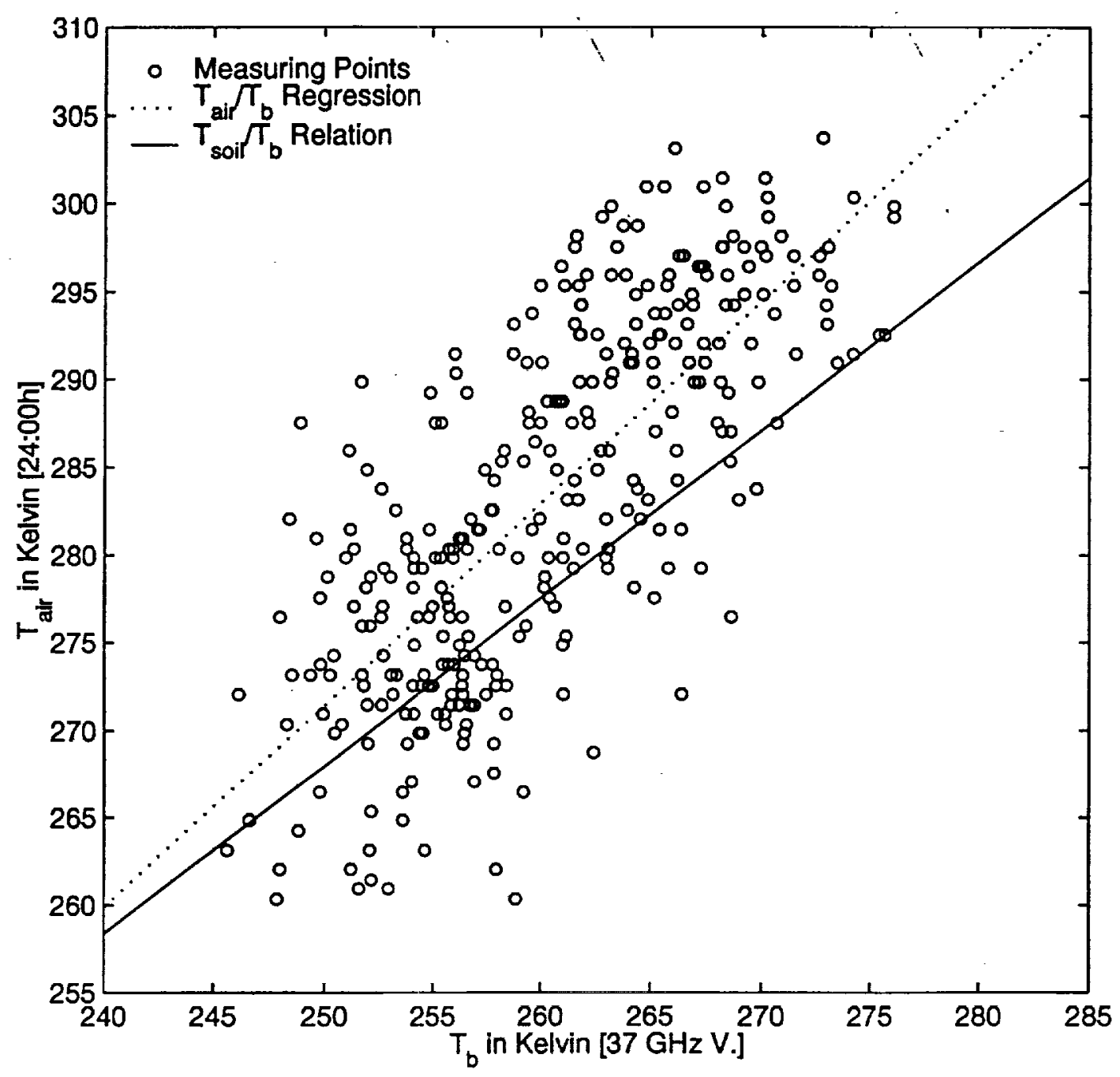




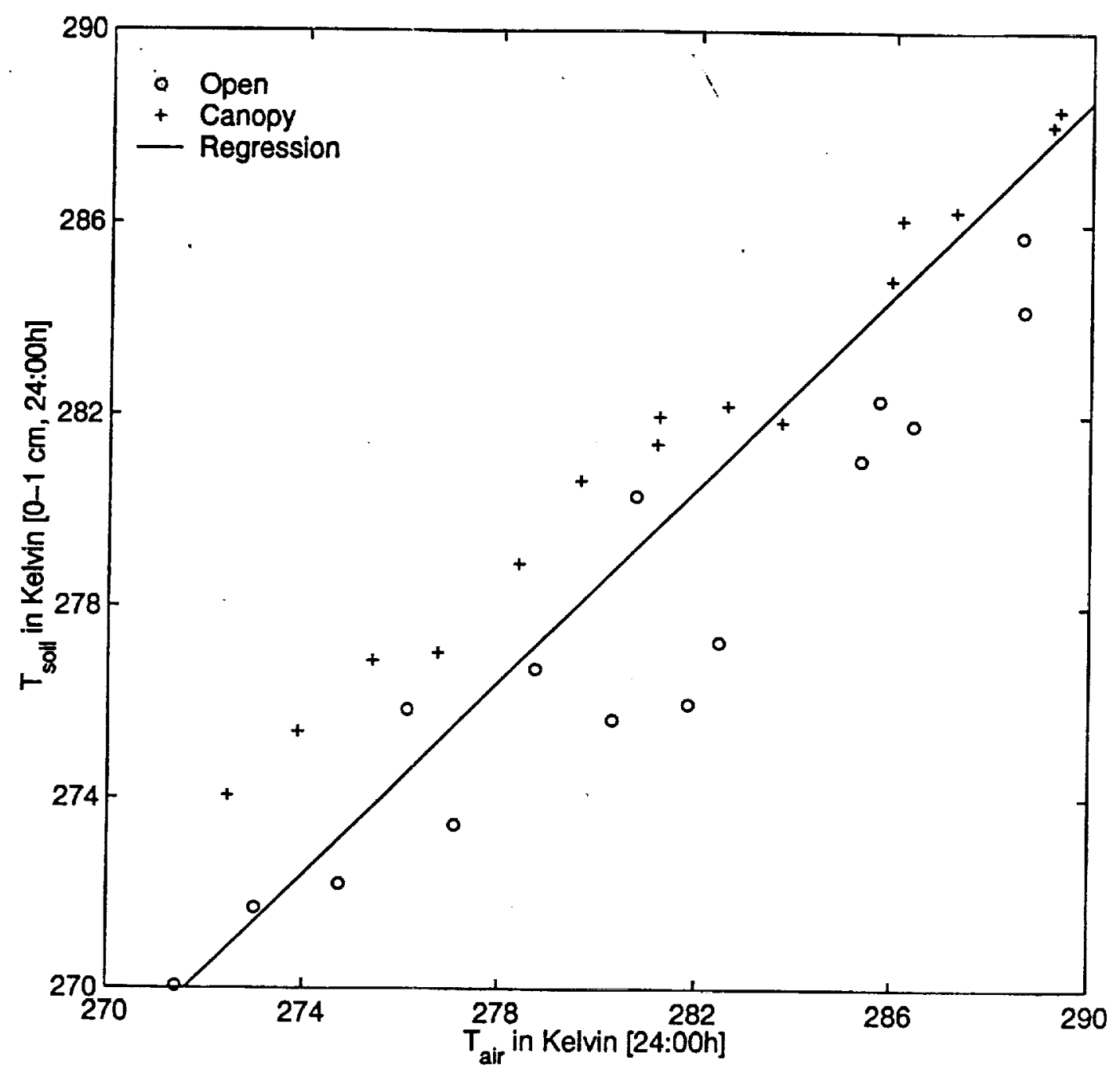

(8) 


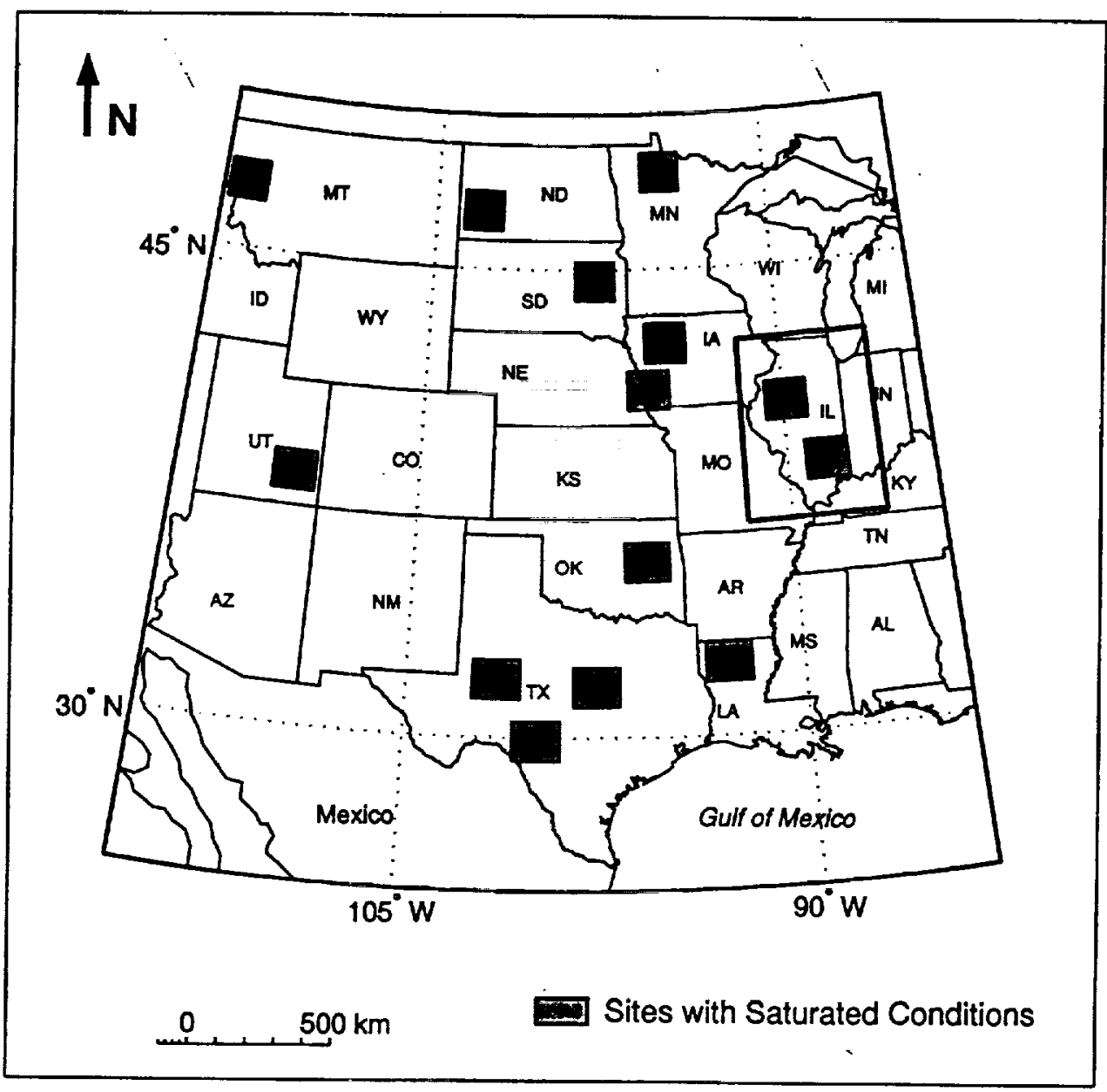




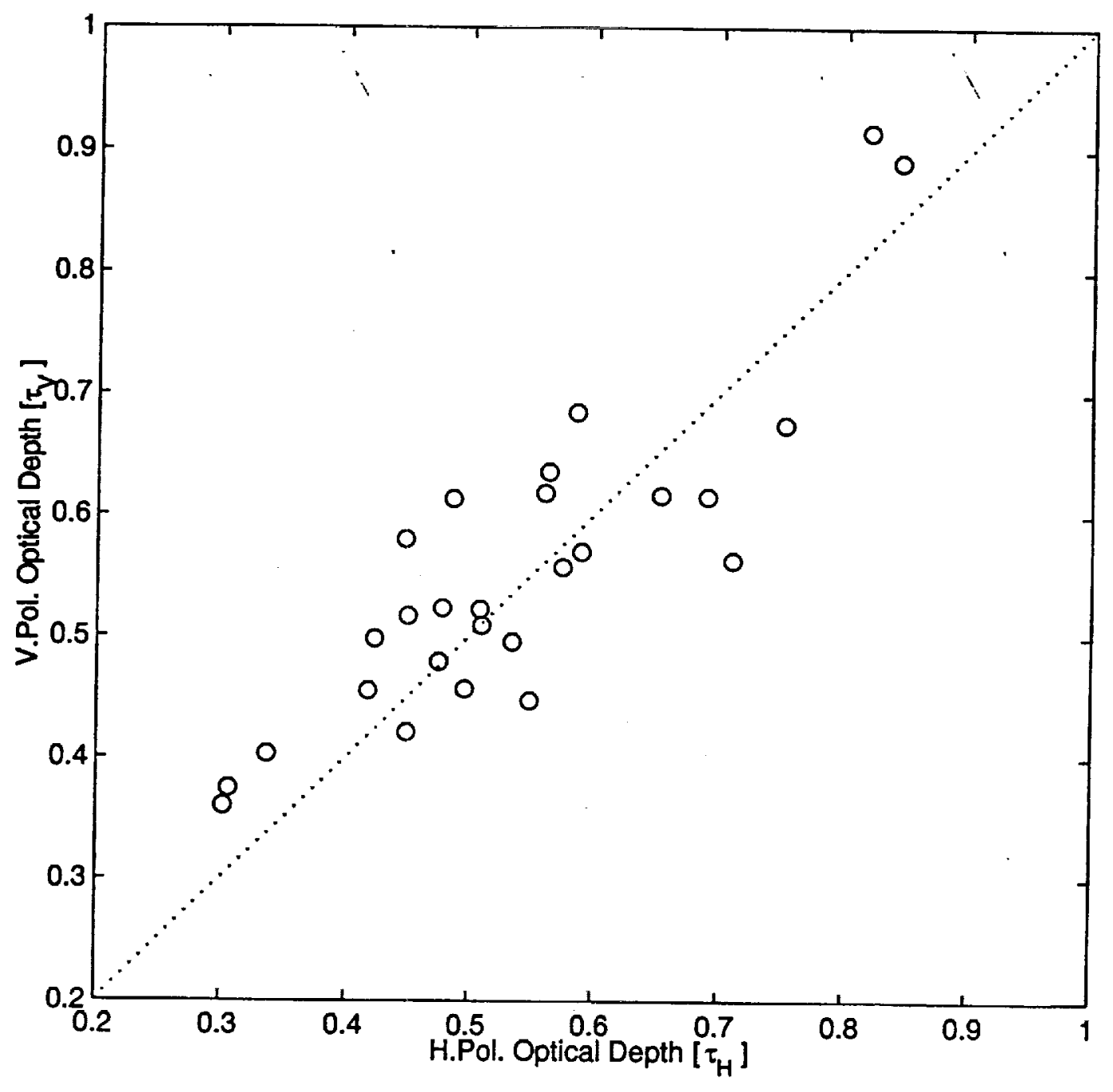

(10) 


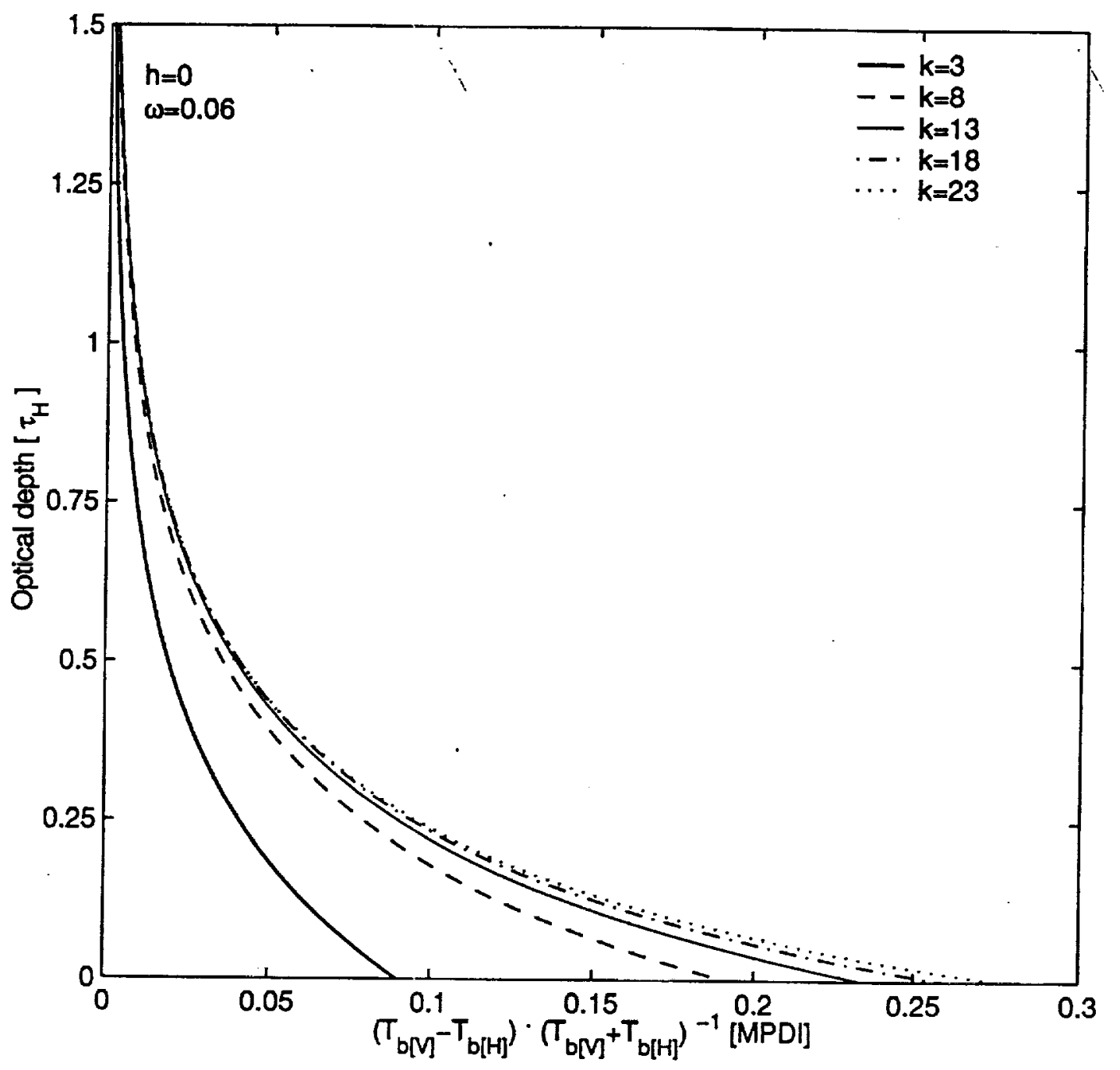

(11) 

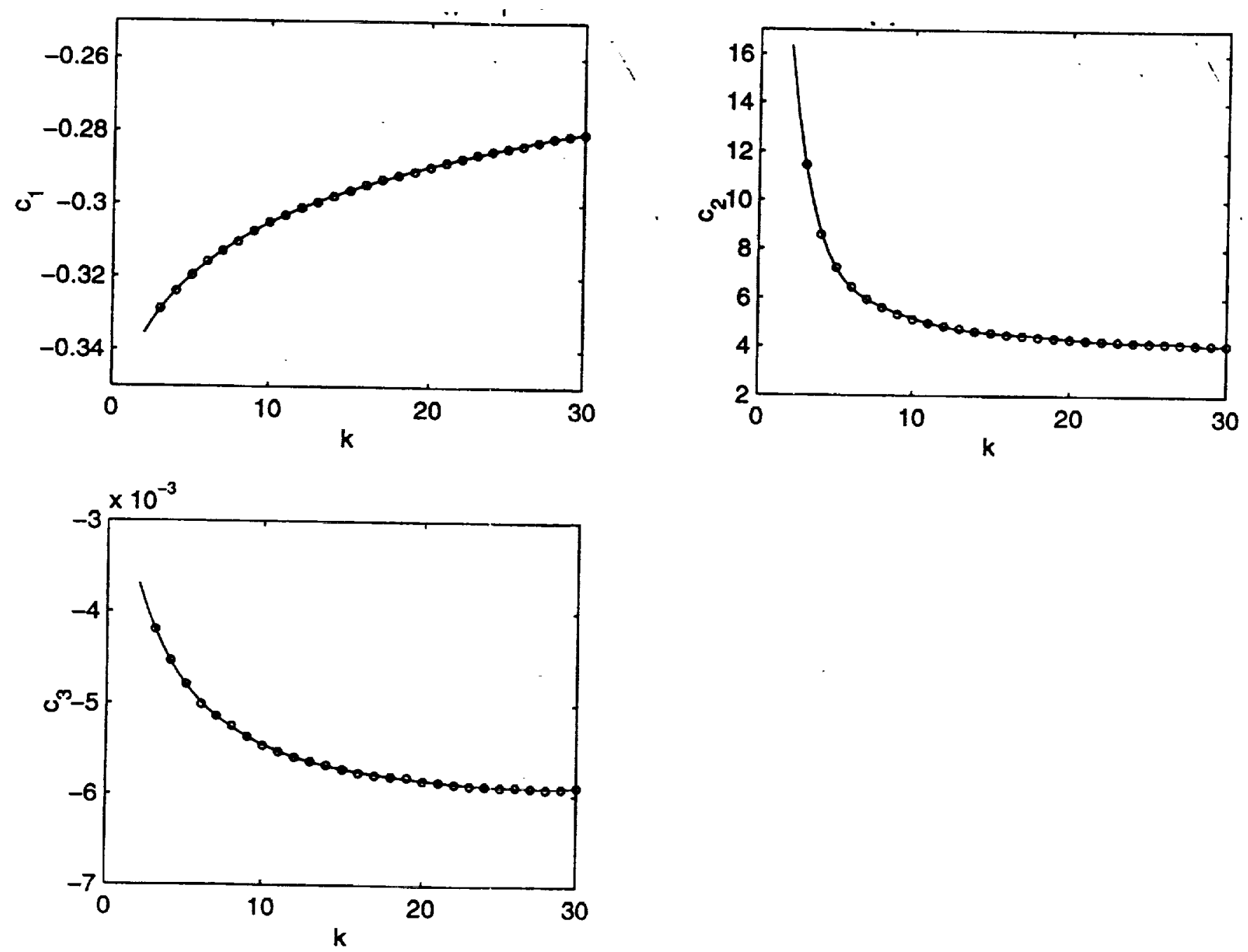


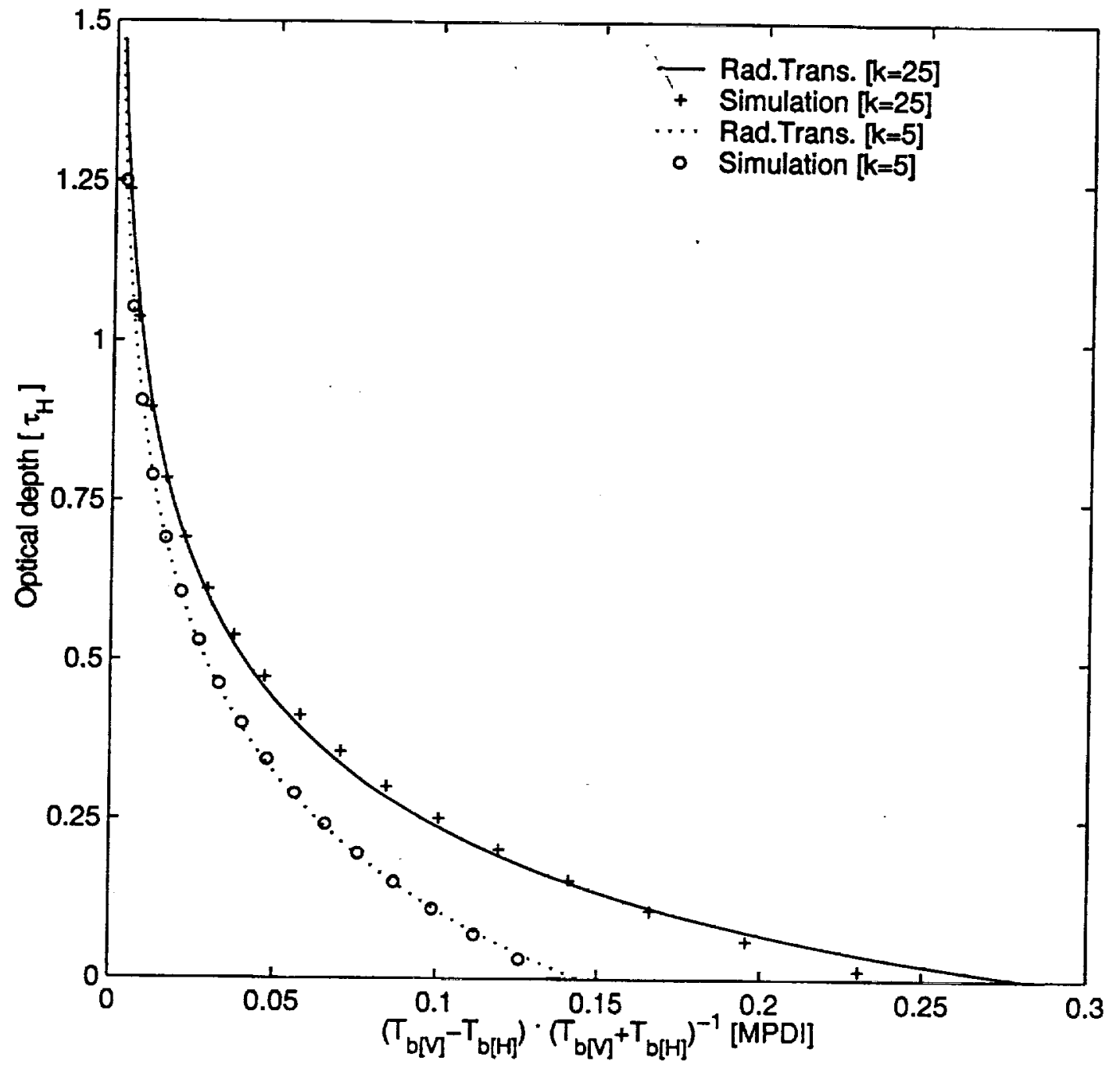




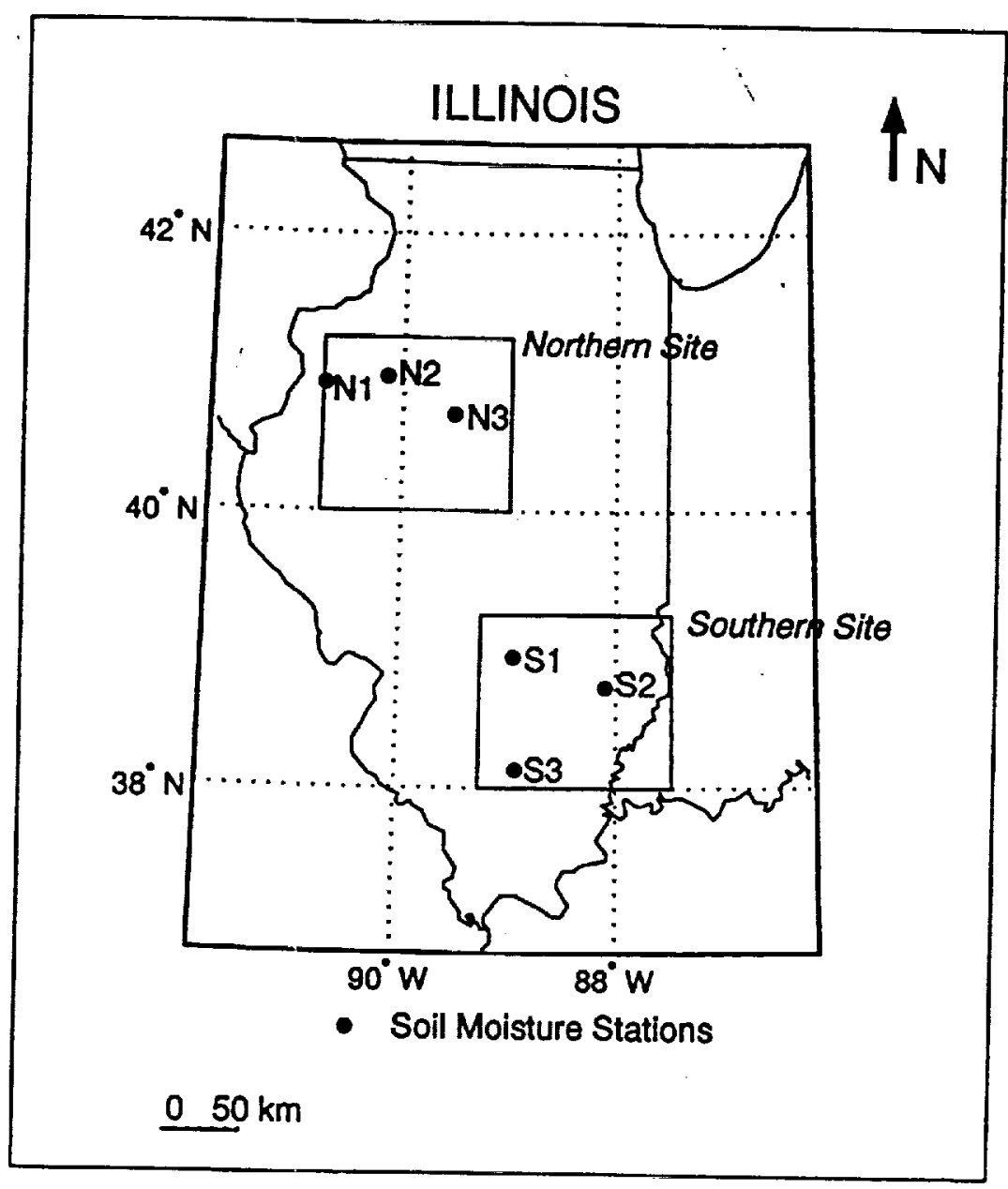




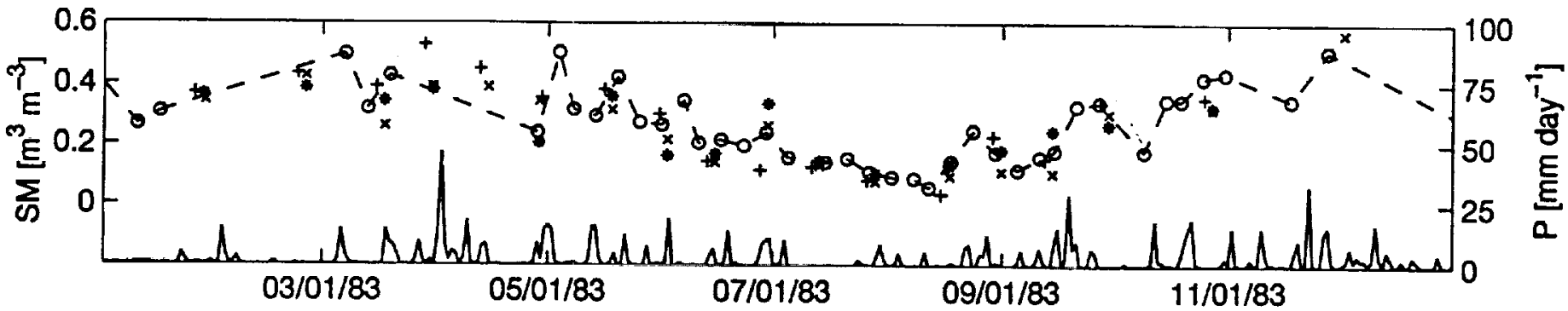

-

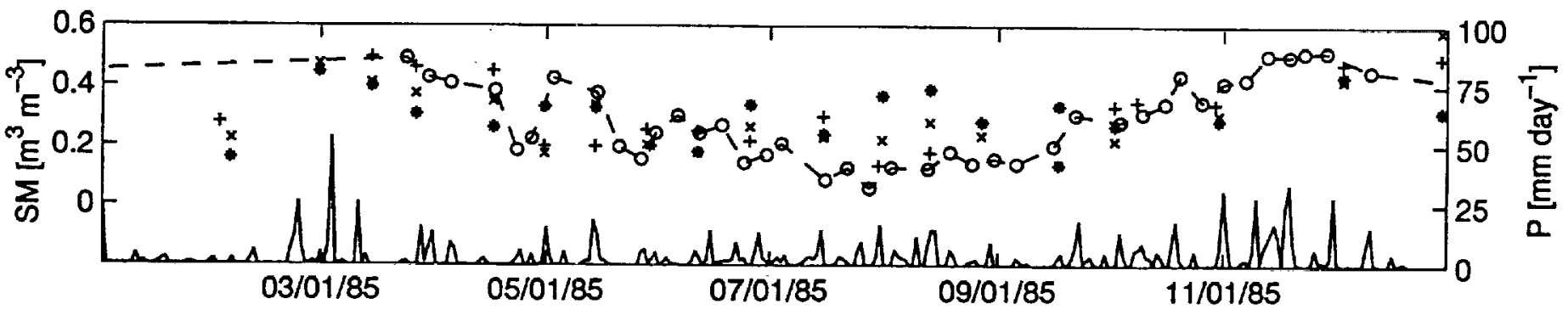

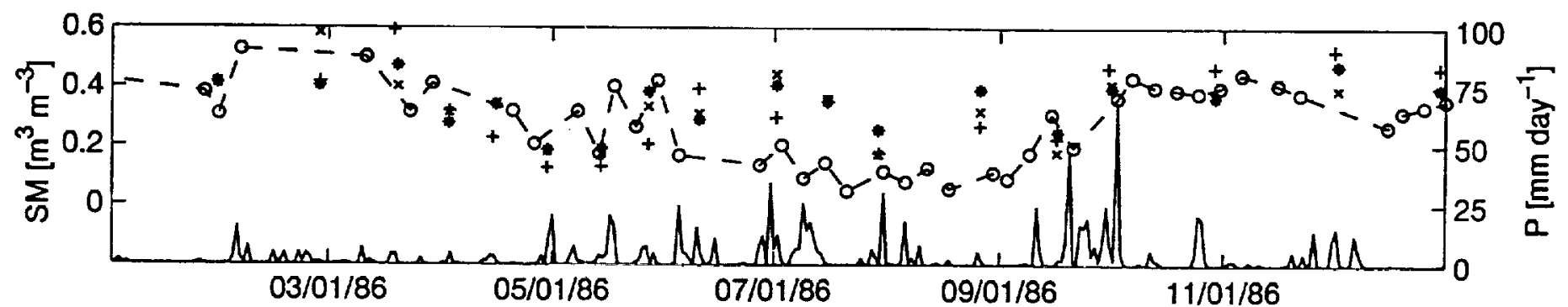

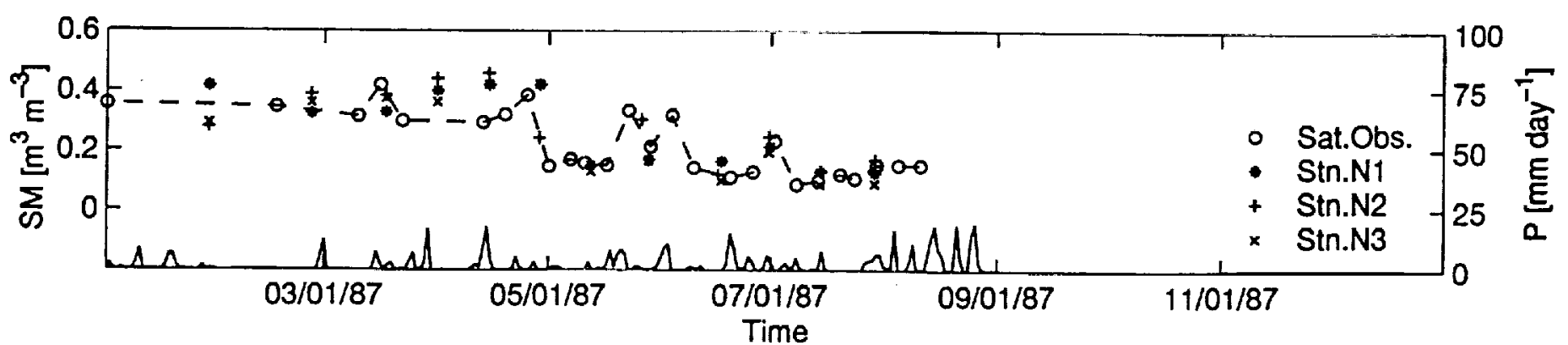



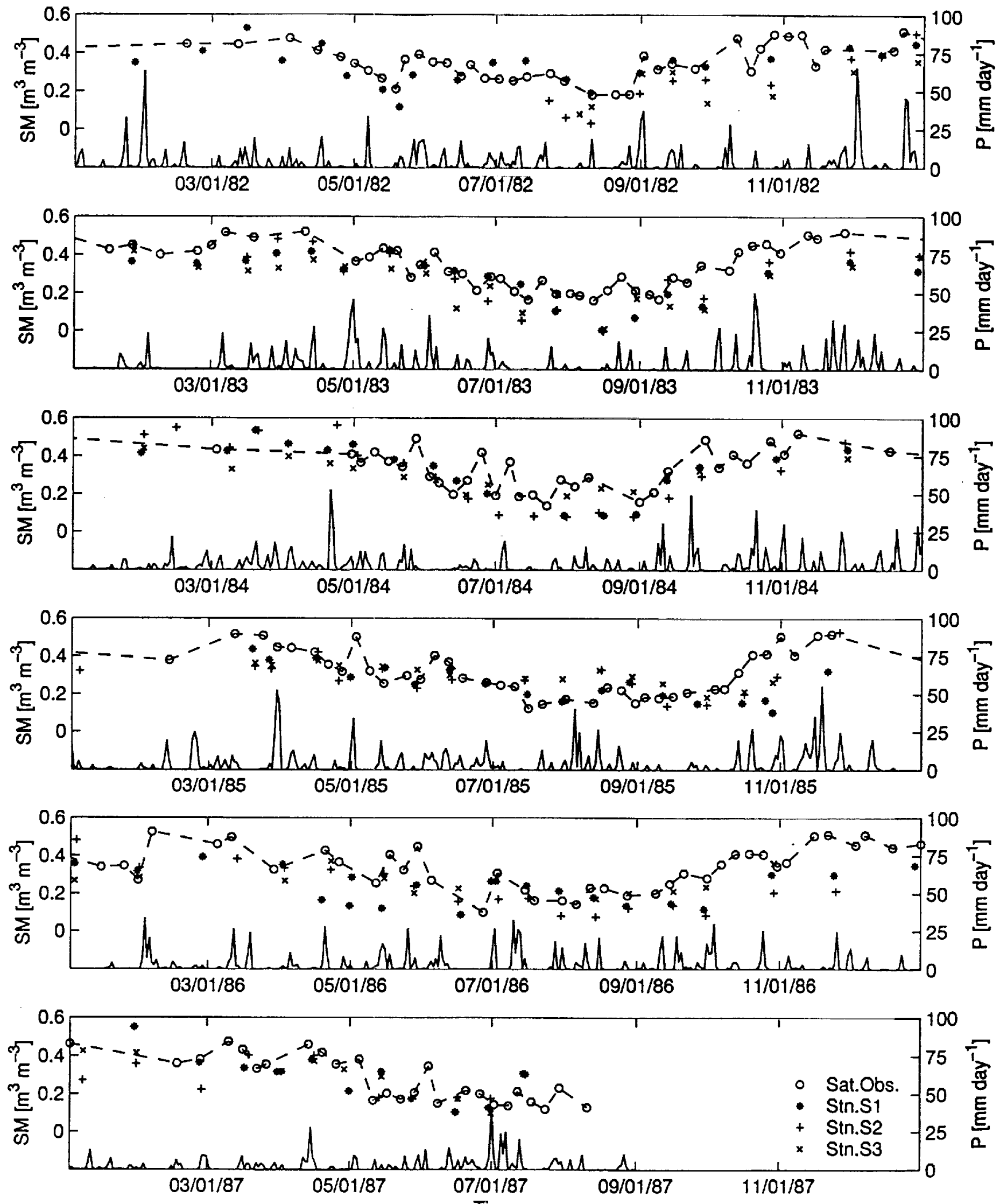

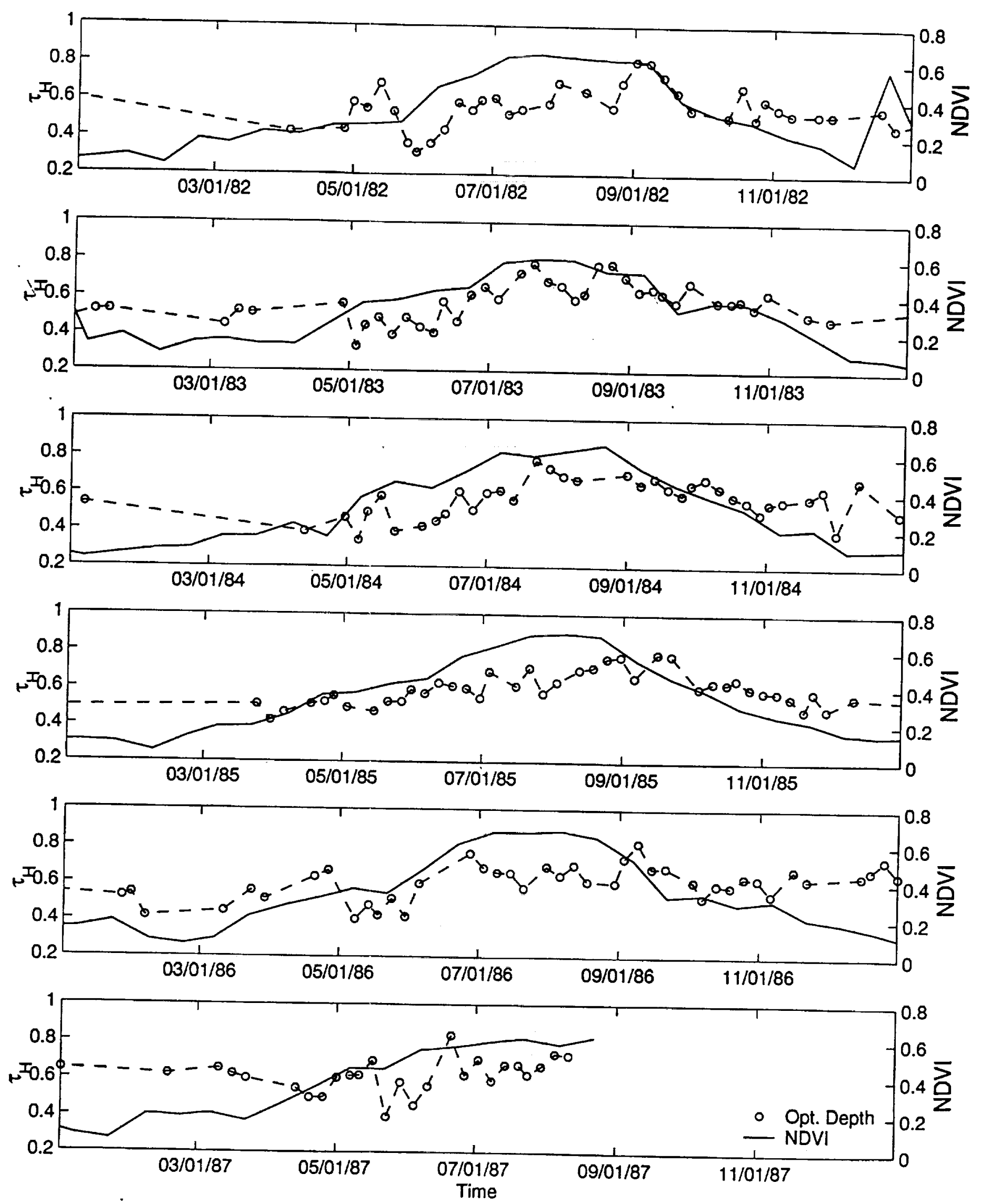

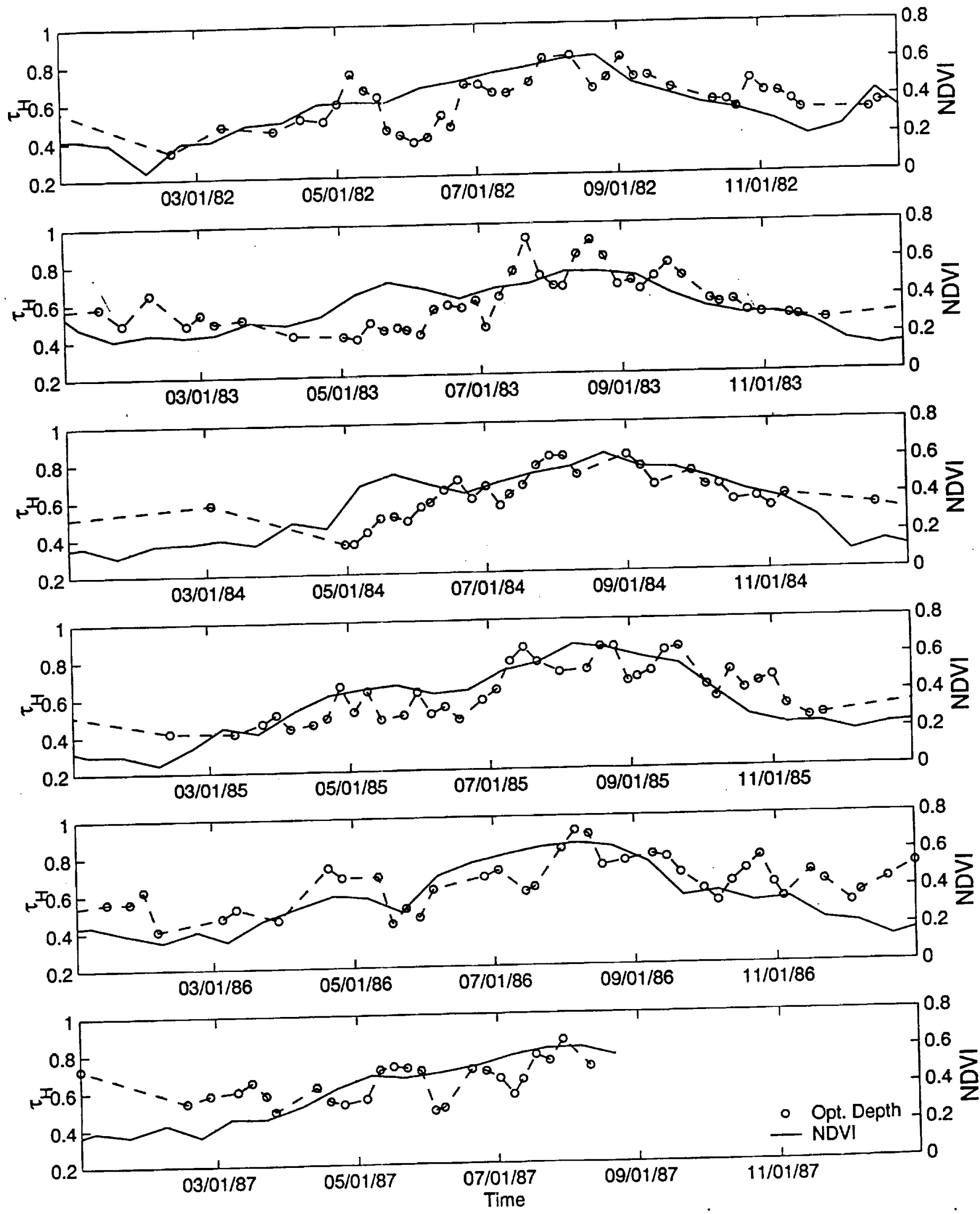